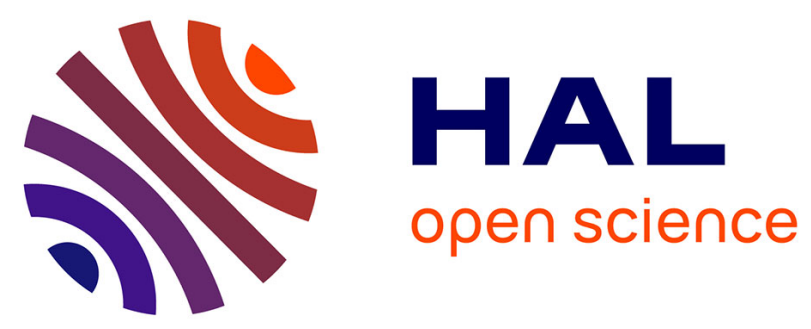

\title{
A role for b2* nicotinic receptors in a model of local amyloid pathology induced in dentate gyrus
}

\author{
Sylvia Lombardo, Julie Catteau, Morgane Besson, Uwe Maskos
}

\section{To cite this version:}

Sylvia Lombardo, Julie Catteau, Morgane Besson, Uwe Maskos. A role for b2* nicotinic receptors in a model of local amyloid pathology induced in dentate gyrus. Neurobiology of Aging, 2016, 46, pp.221-234. 10.1016/j.neurobiolaging.2016.06.005 . hal-01573489

\section{HAL Id: hal-01573489 \\ https://hal.science/hal-01573489}

Submitted on 10 Aug 2017

HAL is a multi-disciplinary open access archive for the deposit and dissemination of scientific research documents, whether they are published or not. The documents may come from teaching and research institutions in France or abroad, or from public or private research centers.
L'archive ouverte pluridisciplinaire HAL, est destinée au dépôt et à la diffusion de documents scientifiques de niveau recherche, publiés ou non, émanant des établissements d'enseignement et de recherche français ou étrangers, des laboratoires publics ou privés. 


\title{
A role for $\beta 2^{*}$ nicotinic receptors in a model of local amyloid pathology induced in dentate gyrus
}

\author{
Sylvia Lombardo ${ }^{\mathrm{a}, \mathrm{b}, 1}$, Julie Catteau ${ }^{\mathrm{a}, \mathrm{b}}$, Morgane Besson ${ }^{\mathrm{a}, \mathrm{b}}$, Uwe Maskos ${ }^{\mathrm{a}, \mathrm{b}, *}$ \\ a Institut Pasteur, Département de Neuroscience, Unité Neurobiologie intégrative des systèmes cholinergiques, Paris, France \\ ${ }^{\mathrm{b}}$ CNRS, UMR 3571, Paris, France
}

\section{A R T I C L E I N F O}

Article history:

Received 7 August 2015

Received in revised form 22 May 2016

Accepted 9 June 2016

Available online 17 June 2016

\section{Keywords:}

In vivo amyloid pathology

Amyloid precursor protein

$\alpha 7$ nicotinic receptor

$\beta 2$ nicotinic receptor

Memory deficit

Hippocampus

\begin{abstract}
A B S T R A C T
Alzheimer's disease (AD) is characterized by the presence of plaques and tangles. Only certain brain regions are vulnerable to progressive neurodegeneration. It is therefore important to study the contribution of key brain structures to AD pathology. Here, we investigated the consequences of amyloid accumulation specifically in dentate gyrus (DG). This was obtained with viral transduction of human amyloid precursor protein harboring 3 pathogenic mutations (hAPP-SLA, Swedish, London, and Austrian) in DG. Adult wild-type C57Bl/6J mice exhibited long-term expression of hAPP-SLA, synthesis and deposition of oligomeric amyloid beta $(A \beta)$, and associated memory impairment. We then investigated the role of $\alpha 7$ or $\beta 2$ subunits of the nicotinic acetylcholine receptor by transducing hAPP-SLA into C57Bl/ $6 \mathrm{~J}$ mice knock-out (KO) for $\alpha 7$ or $\beta 2$ subunits. $\beta 2$ KO mice did not exhibit memory loss induced by hAPPSLA expression, whereas aged mice lacking the $\alpha 7$ subunit displayed a hAPP-SLA independent cognitive deficit. The present data reveal a role for $\beta 2$ containing nicotinic acetylcholine receptors in the memory deficits associated with DG specific amyloid beta expression.
\end{abstract}

(c) 2016 Elsevier Inc. All rights reserved.

\section{Introduction}

Alzheimer's disease $(A D)$ is a progressive neurodegenerative disease, characterized by the spread of hallmark lesions, which are amyloid extracellular plaques and intracellular neurofibrillary tau tangles. Although AD has widespread effects throughout the brain, only a few neural systems are specifically involved and show consistent pathologic changes (Braak and Braak, 1991). Notably, the cholinergic pathway and neurons located in the basal forebrain are highly subject to degeneration in AD (Auld et al., 2002; Whitehouse et al., 1982). These basal forebrain neurons provide the primary cholinergic innervation to the neocortex, hippocampus, and other limbic regions (Woolf and Butcher, 2011). Moreover, AD has also been consistently associated with a considerable loss of high-affinity nicotinic acetylcholine receptors (nAChRs) that contain the $\beta 2$ subunit (Gotti et al., 2006). This loss occurs particularly in temporal cortex and hippocampus. Decreased protein levels of $\alpha 7 \mathrm{nAChRs}$ were also reported in AD brains (Nordberg, 2001). Because nAChRs are implicated in cognitive processing, such as working memory and

\footnotetext{
* Corresponding author at: Neurobiologie intégrative des systèmes cholinergiques, CNRS UMR 3571, Département de Neuroscience, Institut Pasteur, 25 rue du Dr Roux, 75724 Paris, France. Tel.: +33 1456888 06; fax: +33 144389158 .

E-mail address: umaskos@pasteur.fr (U. Maskos).

1 Present address: Alzheimer's Disease Research Laboratory, Department of Neuroscience, Tufts University School of Medicine, Boston MA USA.
}

attention, they have been proposed to contribute to the cognitive decline observed in normal and pathologic aging. Notably, amyloid pathology could be the link between cholinergic neuron degeneration and cognitive deficit in AD (Okada et al., 2013).

Numerous transgenic mouse models used to study AD express ubiquitously and constitutively familial AD-associated mutations (Epis et al., 2010; LaFerla and Green, 2012). Other models such as doxycycline inducible systems allow a temporal control of amyloid precursor protein (APP) expression (Jankowsky et al., 2005). However, all these lines develop amyloid aggregation in the whole brain. This is in many cases linked to rapid and severe biochemical and pathologic changes and does not allow to investigate the implication of a discrete brain region in $\mathrm{AD}$. Therefore, we sought to develop a novel mouse model to induce amyloid deposition, in a specific region of the brain, in adult animals. This approach allows us to accurately investigate the contribution of specific brain areas to AD pathology. The model was obtained with the use of a lentiviral vector for in vivo transduction of a mutated form of the human APP harboring 3 pathogenic mutations: Swedish, London and Austrian (hAPP-SLA). These mutations were selected because of their ability to increase amyloid beta (A $\beta$ ) synthesis (Goate et al., 1991; Kumar-Singh et al., 2000; Mullan et al., 1992). We targeted the transduction of hAPP-SLA in the dentate gyrus (DG) of the hippocampus for its key role in memory formation (Morris, 2006; Squire et al., 2007) and its crucial implication in AD pathology (Ohm, 2007). Wild-type (WT) mice 
transfected with hAPP-SLA developed AD-like pathologic features such as memory loss and $A \beta$ deposition that was restricted to the targeted area. We then used this methodology to characterize the role of nAChRs in memory dysfunction caused by amyloid pathology. Both $\alpha 7$ and $\beta 2$ nAChR subunits are widely expressed in the hippocampus (Jones and Yakel, 1997), which receives cholinergic afferents from the basal forebrain (Woolf and Butcher, 2011). Because an interaction between $\alpha 7$ and $\beta 2 \mathrm{nAChR}$ subunits and $\mathrm{A} \beta$ has been reported, we focused our study on these nAChR subunits (Liu et al., 2009, 2012; Nordberg et al., 1995; Wang et al., 2000b, reviewed in, 2000a; Lombardo and Maskos, 2015). The hAPP-SLA was transduced into mice harboring null mutations for $\alpha 7$ ( $\alpha 7$ knock-out [KO] mice) or $\beta 2$ ( $\beta 2 \mathrm{KO}$ mice) subunits to investigate their respective contribution to AD phenotypes.

\section{Materials and methods}

\subsection{Lentiviral construction}

The lentiviral vector used in this study derived from the third generation systems (Dull et al., 1998). Their principal characteristics are a self-inactivating deletion in the U3 region of the $3^{\prime} \mathrm{LTR}$, a chimeric 5'LTR, and a woodchuck hepatitis virus posttranscriptional regulatory element sequence (Dull et al., 1998; Zufferey et al., 1999).

LV pTripPGK-hAPP-SLA-FLAG-IRES-eGFP (hAPP-SLA): the hAPP complementary DNA (cDNA) harboring the Swedish mutation (KM670/671NL) was recovered from a pcDNA 3.1 plasmid. The cDNA sequence was modified with directed mutagenesis PCR (Agilent Technologies, Stratagene, Santa Clara, CA, USA) to add London (V717I) and Austrian (T714I) mutations (for primers used see Table 1). The same procedure was used to delete the stop codon at APP $3^{\prime}$ to add an FLAG tag. The obtained construct was inserted into a pGEM-T vector (Promega, Madison, WI, USA), resulting in the hAPP-SLA-FLAG-pGEMT plasmid. The hAPP-SLA-FLAG cassette was recovered from pGEM-T vector with Xmal and NheI restriction enzymes and inserted in an LV pTripPGK vector digested with the same enzymes, downstream of the PGK promoter and upstream of the internal ribosome entry siteenhanced green fluorescent protein (IRES-eGFP) sequence. The resulting lentiviral vector was a pTripPGK-hAPP-SLA-FLAG-IRES-eGFP. The lentivirus obtained coexpresses hAPP-SLA and eGFP, the latter being used as reporter gene for the analysis of lentiviral infection diffusion in the selected area.

\subsection{Viral production and titration}

The vector plasmid, packaging plasmid (CMV $\Delta .9$ ), and envelope plasmid (CMV-VSVg) were cotransfected in HEK293T cells with Lipofectamine Plus (Life Technologies, Invitrogen, Carlsbad, CA, USA)

Table 1

List of primers used in the present work

\begin{tabular}{ll}
\hline Primer & Sequence \\
\hline London mutation & F: GCGATAGTGATCATCATCACCTTGGTGATGCTG \\
& R: CAGCATCACCAAGGTGATGATGATCACTATCGC \\
Austrian mutation & F: CGGTGTTGTCATAGCGATAGTGATCGTCATCACC \\
& R: GGTGATGACGATCACTATCGCTATGACAACAAC \\
hAPP-SLA amplification & F: GTTGTCATAGCGATAGTGATCA \\
& R: GGTCTTTGTAGTCTGTACAC \\
GFP amplification & F: GACGTAAACGGCCACAAGTT \\
& R: CATGGCGGACTTGAAGAAGT \\
Actin amplification & F: CGCCCTAGGCACCA \\
& R: GTTGGCCTTAGGGTTCA \\
\hline
\end{tabular}

The mutations added are highlighted in bold, in primers used for directed polymerase chain reaction mutagenesis.

Key: F, forward primer; hAPP-SLA, human APP with Swedish, London, and Austrian mutations; $\mathrm{R}$, reverse primer. according to the manufacturer's instructions. After 48 hours of expression, viral particles were collected from cell medium, treated with DNaseI (1:5000; $0.2 \mu \mathrm{m} / \mathrm{mL})$ and $\mathrm{MgCl}_{2} 2 \mathrm{M}(1 \mu \mathrm{L} / \mathrm{mL})$, filtered with $0.45-\mu \mathrm{m}$ pore filters (Merk Millipore, Darmstadt, Germany), concentrated by ultracentrifugation, and stored at $-80^{\circ} \mathrm{C}$ until use. The titers were determined by quantifying the p24 capsid protein using an HIV-p24 antigen immunoassay (Gentaur Molecular Products, Kampenhout, Belgium) according to the manufacturer's instructions. Before stereotaxic injections, viral stocks were diluted to the concentration of $100 \mathrm{ng} / \mu \mathrm{L}$ of p24 protein with phosphatebuffered saline (PBS), and a volume of $2 \mu \mathrm{L}$ was injected.

\subsection{Animals}

Experiments were performed with male WT mice (C57Bl/6J line) and $\alpha 7 \mathrm{KO}$ or $\beta 2 \mathrm{KO}$ mice. The mutant lines were generated as previously described (Orr-Urtreger et al., 1997; Picciotto et al., 1995) and are both maintained on a $100 \%$ pure C57Bl/6J background. Mice were bred at Charles River Laboratories in isolators under a 12 hour light-dark cycle. All mice were transported to our facilities at 10 weeks of age, housed under a 12 hour light-dark cycle with ad libitum access to food and water.

\subsection{Stereotaxic injections}

12-week-old mice were anesthetized with $1.5 \%$ ketamine (Merial, Lyon, France) plus 0.05\% xylazine (Bayer Healthcare, Lille, France), in PBS. A stereotaxic frame adapted for mice was used. Lentiviruses ( $2 \mu \mathrm{L}$ at $100 \mathrm{ng} / \mu \mathrm{L}$ ) were injected bilaterally (flow rate $0.2 \mu \mathrm{L} / \mathrm{min}$ ). The following coordinates for the DG were used, according to the Paxinos and Franklin Atlas (Paxinos and Franklin, 2004): A/P: $-1.8, \mathrm{M} / \mathrm{L}: \pm 1.2$, and $\mathrm{D} / \mathrm{V}:-1.9$.

\subsection{Total RNA extraction and messenger RNA ( $m R N A)$ amplification}

Mice were deeply anesthetized with a lethal dose of ketamine/ xylazine. Intracardial perfusion with PBS was performed, and hippocampi were dissected and collected. The tissue was homogenized with a pestle in Trizol (Life Technologies, Ambion, Carlsbad, CA, USA). Consecutive steps of centrifugation were performed with chloroform (Sigma-Aldrich, Saint Louis, MO, USA) and isopropanol (Sigma-Aldrich). Finally, the samples were centrifuged, the pellet recovered, resuspended in sterile water, and stored at $-80{ }^{\circ} \mathrm{C}$ until use. Reverse transcription was performed with the commercial kit Superscript Vilo cDNA synthesis (Life Technologies, Invitrogen) according to the manufacturer's instructions. Primers used for amplification are listed in Table 1. Primers were designed against the hAPP sequence to avoid any amplification of murine APP.

For behavioral experiments, 2 groups of mice were injected at 12 weeks of age. One group was injected with the hAPP-SLA lentivirus (APP-WT; APP- $\alpha 7$, and APP- $\beta 2$ groups), and the control group was injected with a lentivirus expressing only GFP (GFP-WT; GFP- $\alpha 7$, and GFP- $\beta 2$ groups).

\subsection{Novel place recognition (NPR)}

Recognition memory was evaluated in a "novel place recognition" procedure as a simple behavioral assay of memory that primarily relies on rodent's propensity to explore novelty in the absence of external rules of reinforcement. C57Bl/6J mice exhibit a spontaneous tendency to explore novelty in free-exploratory paradigms. We evaluated the ability of recognizing a previously presented environment versus a novel one, by measuring the difference in the exploration time of the familiar and novel environments. The boxes used were composed of 2 equal compartments $(16 \times 16 \mathrm{~cm})$ 
connected by a central zone $(16 \times 5 \mathrm{~cm})$. Boxes were made of gray Plexiglass and were closed at the time of the experiments to be isolated from visual cues in the testing room. Light intensity in the boxes was approximately 15-20 lux. The 2 compartments showed 2 distinct spatial configurations (1 rectangular or 2 triangular object(s) at 1 or 2 of the angles) and 2 distinct floor textures (grooves or peaks). The apparatus was equipped with infrared frame detectors to record the activity of the animals in each compartment. Mice were left 3 minutes in the central zone before being confined for $20 \mathrm{mi}$ nutes in 1 of the 2 compartments ("familiar"). The mice were then placed back into their home cage for 15 minutes. During the following test phase, the animal was allowed to explore the whole box (central zone, familiar, and new compartment) for 15 minutes. The time spent in the familiar compartment and the time spent in the novel compartment were quantified. Before starting the experiments, we previously verified, in separate groups of animals, that (1) C57Bl/6J mice show a robust preference for the novel compartment when tested with no delay between the confinement and the test phases, (2) C57B16/J mice are able to discriminate both environments, and (3) the absence of spontaneous preference for one of the compartments (data not shown). Mice were tested 7 months post injection (p.i.). Data were analyzed with a paired 2-tailed Student's $t$ test. Results are presented as mean \pm standard error of the mean $\left(\mathrm{SEM} ;{ }^{*} p<0.05 ;{ }^{* *} p<0.01\right.$; and $\left.{ }^{* * *} p<0.001\right)$.

\subsection{Novel object recognition (NOR)}

Recognition memory was also evaluated with a novel object recognition task using a rectangular open field $(50 \times 25 \mathrm{~cm})$ made of transparent Plexiglass. Before starting the experiment, we verified that mice did not display a preference among the different objects used. Mice were subjected to a 10 minute-training session in which they were allowed to explore 2 copies of the same object (A or B). Mice were placed back in their home cage for a retention interval of 15 minutes then tested in a session of 10 minutes with 2 objects, 1 familiar and 1 novel (A or B). Light intensity in the room was approximately 50 lux. Each session was recorded, and the time spent exploring the objects was evaluated manually by an operator blinded to experimental group. Exploration of an object was defined as the animal's nose being directed toward the object within a certain radius around it. The use of object A or B as familiar or novel object was randomized among mice to avoid any bias. The objects used were a glass cylinder (height: $19 \mathrm{~cm}$, diameter: $4 \mathrm{~cm}$ ) and a plastic cube (height: $7.2 \mathrm{~cm}$, length $6.4 \mathrm{~cm}$, and width: $2.4 \mathrm{~cm}$ ). The distance between objects was $30 \mathrm{~cm}$. Mice that climbed the objects or displayed very low object exploration (less than 5 seconds) were excluded from the study. Mice were tested 15 months p.i. Data were plotted as total exploration time and recognition percentage (TimeNovel/[Time Novel + Time $\left.\left._{\text {Familiar }}\right] \times 100\right)$ and analyzed with an unpaired (for recognition percentage) or paired (for total time) 2-tailed Student's $t$-test. Results are presented as mean \pm SEM. Locomotor behavior during the habituation phase was quantified with the software EthoVision XT (Noldus Information Technology, Wageningen, Netherlands). Data were plotted as total distance traveled $(\mathrm{cm})$ and analyzed with an unpaired 2-tailed Student's $t$-test. Results are presented as mean $\pm \operatorname{SEM}\left({ }^{*} p<0.05\right.$; $^{* *} p<0.01$; and $\left.{ }^{* * *} p<0.001\right)$.

\subsection{Light-dark box (LDB)}

Anxiety was evaluated with the LDB paradigm using a rectangular cage $(22 \times 16 \mathrm{~cm})$ made of Plexiglass, divided in 2 sections of equal size, the lit compartment with white walls and the dark with black walls. An illumination of 500 lux was applied to the lit side whereas the dark side was protected from light (about 2-4 lux in the dark compartment). Mice were placed in the dark compartment and allowed to freely explore the box for 5 minutes. The cage was placed on an infrared board, and movies were taken with an infrared camera. Transitions from 1 section to the other of the box and total time spent in each compartment were quantified with the software EthoVision XT (Noldus Information Technology, Wageningen, Netherlands). Mice were tested 12 months p.i. Data were analyzed with an unpaired 2-tailed Student's t-test for both percentage spent in lit compartment $\left(\right.$ Time $_{\text {Lit }} /\left[\right.$ Time $_{\text {Lit }}+$ Time $\left._{\text {Dark }}\right] \times$ $100)$ and number of transitions. Results are plotted as mean \pm SEM $\left({ }^{*} p<0.05 ;{ }^{* *} p<0.01\right.$; and $\left.{ }^{* * *} p<0.001\right)$.

For all behavioral tests, all apparatus were washed with water between individual sessions.

\subsection{Immunostaining}

Mice were deeply anesthetized with a lethal dose of ketamine/ xylazine before intracardiac perfusion with ice cold PBS first, followed by PFA (paraformaldehyde) (Sigma-Aldrich) 4\% in PBS. The brains were collected and postfixed overnight in PFA 4\%. Coronal brain slices of $50-\mu \mathrm{m}$ thickness were obtained using a vibratome (Leica Microsystems, Wetzlar, Germany). Slices were incubated in $10 \%$ normal goat serum and $0.2 \%$ Triton X-100 in PBS for 1 hour, then washed in PBS and incubated with primary antibodies: anti-GFP rabbit 1:2000 (Life Technologies, Invitrogen) or anti-GFP mouse 1:2000 (Millipore), variable domain of heavy chain antibodies (VHH) V31-1 kindly provided by Pierre Lafaye (Lafaye et al., 2009), antiGFAP (glial fibrillary acidic protein) 1:200 (Abcam) and anti-Iba1 (ionized calcium binding adaptor molecule 1) rabbit 1:1000 (Abcam). We used an anti-His antibody (Sigma-Aldrich) to amplify the VHH signal. For the staining with the 7H3D6 antibody (kindly provided by Sathish Kumar and Jochen Walter), an antigen retrieval protocol was performed before incubation with the 7H3D6 antibody (Kumar et al., 2013). Slices were boiled in 0.01-M citrate buffer pH 6 for 15 minutes at $90{ }^{\circ} \mathrm{C}$, then incubated in 5\% skimmed milk $+10 \%$ horse serum in PBS for 1 hour. The rat monoclonal primary antibody 7H3D6 was used at a dilution of 1:500. The fluorophore-conjugated secondary antibodies used were Cy3-conjugated anti-mouse and Cy2-conjugated anti-rabbit, (Jackson Immunoresearch, West Grove, PA, USA) at a dilution of 1:500 and Alexa Fluor 568 anti-rat (Life Technologies, Invitrogen) at a dilution of $1: 100$. After DAPI $\left(4^{\prime}, 6-\right.$ Diamidino-2-phenylindole, Sigma-Aldrich) incubation, the slices were mounted on slides and fixed with ProLong Gold Antifade Reagent (Life Technologies, Molecular Probes, Carlsbad, CA, USA). Sections were imaged with a Zeiss Apotome (at $25 \times$ or $60 \times$ ) and with a Leica SP5 confocal microscope (at $63 \times$ ). All images were analyzed and stitched with Fiji software (Schindelin et al., 2012). Quantification of GFP fluorescence intensity was performed with Icy software (de Chaumont et al., 2012) ( $\mathrm{n}=20 ; 10 \mathrm{GFP}-\mathrm{WT}$ and 10 APP-WT). Three slices from each mouse on the anterior-posterior axis were analyzed (from Bregma: -1.5 for the first slice, -1.9 for the second, and -3 for the last). Fluorescence intensity was normalized on region of interest (ROI) area and is plotted as mean \pm SEM. Fluorescent intensity per ROI area was used as index of number of cells transduced in the targeted area.

Statistical analysis was performed using Excel and GraphPad Prism 5.0 (Graph Pad Software).

\section{Results}

3.1. Stable in vivo transduction of hAPP-SLA restricted to DG induces memory deficit

We generated a lentiviral vector encoding the human sequence of the APP harboring 3 pathogenic mutations, the Swedish double mutation (KM670/671NL) (Mullan et al., 1992), the London 
A
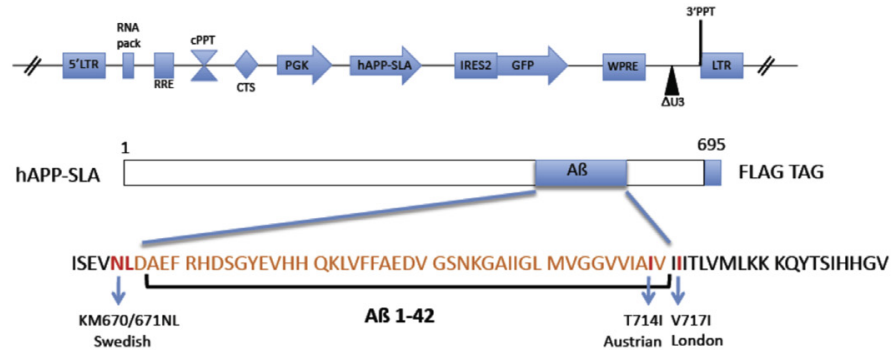

B
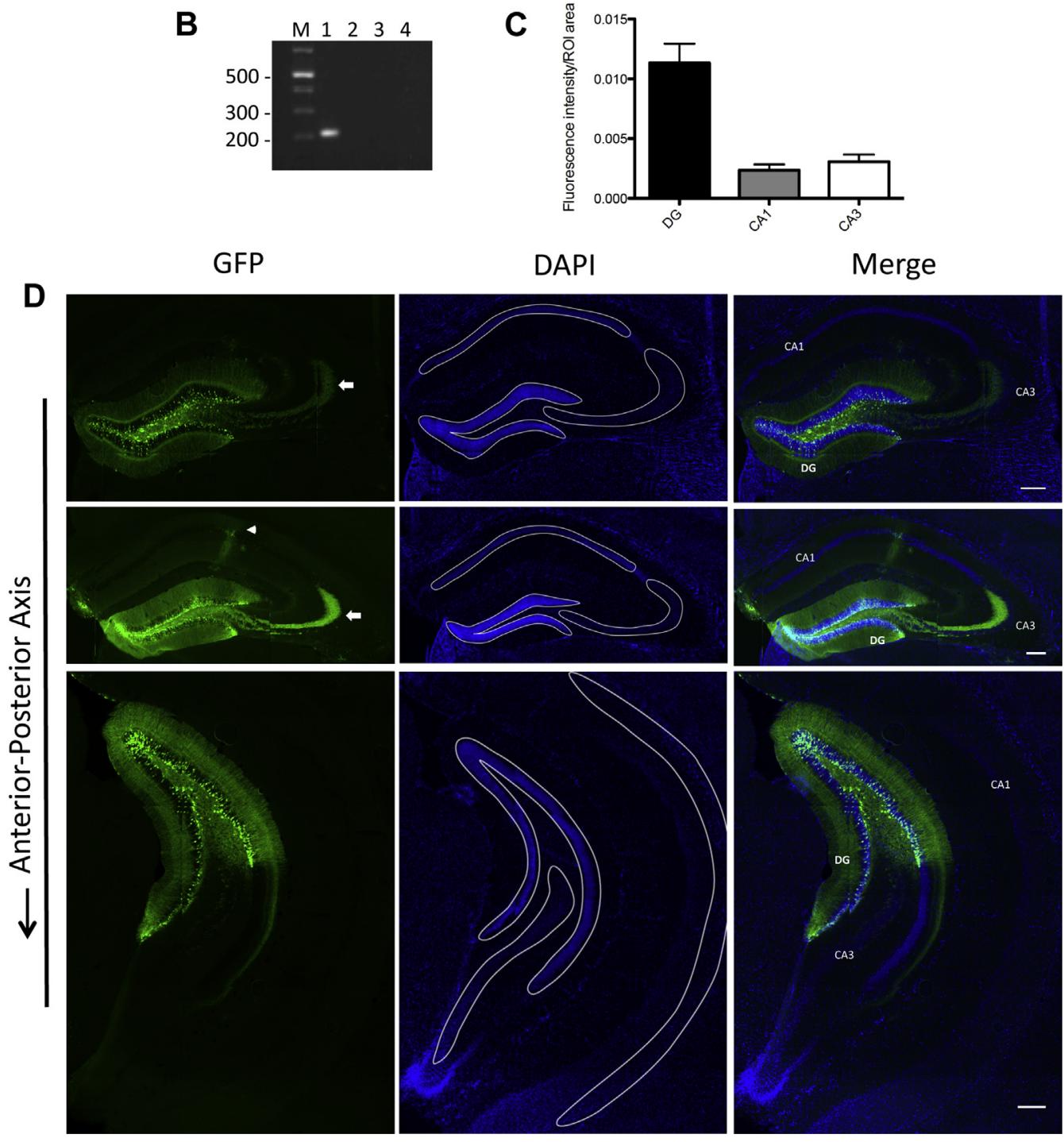

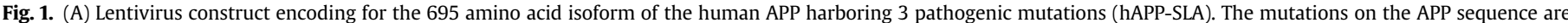

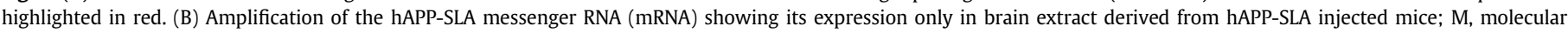

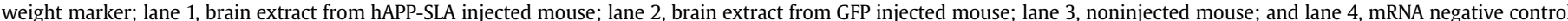

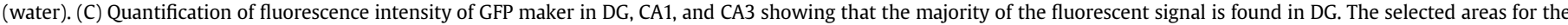

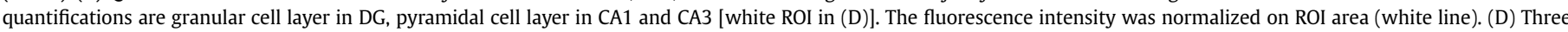

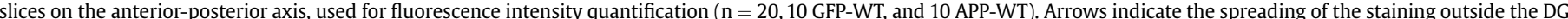

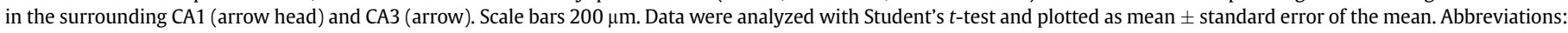

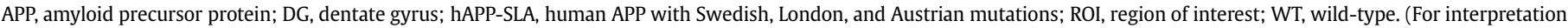
of the references to color in this figure legend, the reader is referred to the Web version of this article.)

mutation (V717I) (Goate et al., 1991), and the Austrian mutation (T714I) (Kumar-Singh et al., 2000) (Fig. 1A). We stereotactically delivered hAPP-SLA into the DG of 12-week-old WT mice to induce $\mathrm{A} \beta$ synthesis only in this area. The viral transduction was verified
1 month p.i. by amplification of mRNA molecules encoding for hAPP-SLA and GFP. The APP sequence was amplified in the APP-WT group and not in GFP-WT group (Fig. 1B), whereas the GFP sequence was amplified in both groups (data not shown). We then evaluated 
the extension of the viral transduction in the targeted area using GFP protein staining as a marker. The GFP staining (green) showed a widespread diffusion in the DG (Fig. 1D), with little spreading in the surrounding regions of CA1 (Fig. 1D, arrow head) and CA3 (Fig. 1D, arrow). We then quantified GFP fluorescence intensity per ROI area in DG granular cell layer, CA1 and CA3 pyramidal cell layers (Fig. 1D, white lines represent ROIs). The quantification confirmed that the majority of the transduced cells were located in the DG (fluorescence intensity 3-fold higher compared with CA1 and CA3; Fig. 1C). The viral infection was therefore restricted to this area. In addition, we obtained a stable expression of hAPP-SLA and GFP that lasted up to 15 months p.i., as shown in Figs. 6, 7, and 8.

\subsection{In vivo hAPP-SLA expression induces a memory deficit}

Behavioral tasks were carried out to assess recognition memory performance of mice expressing hAPP-SLA specifically in the DG. At 7 months p.i. mice were tested in the NPR paradigm. The analysis of total time of exploration for the novel and familiar compartments during the test phase revealed a significant preference for the novel
A

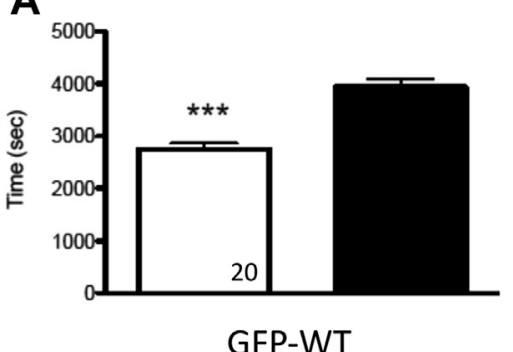

C

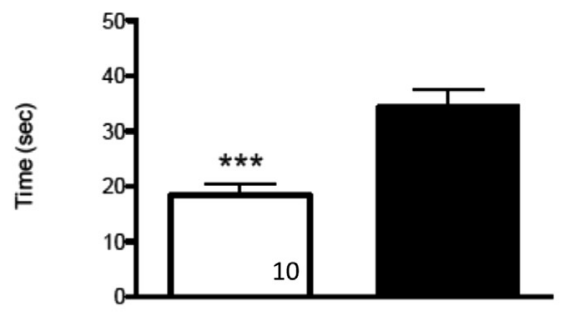

GFP-WT

E

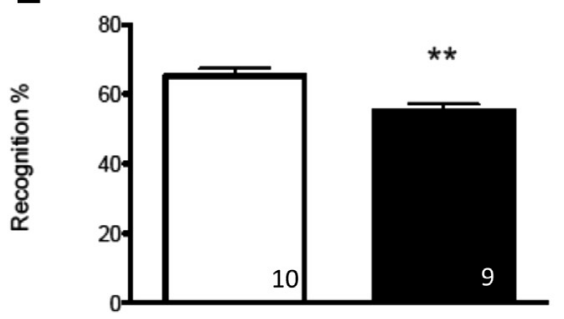

G

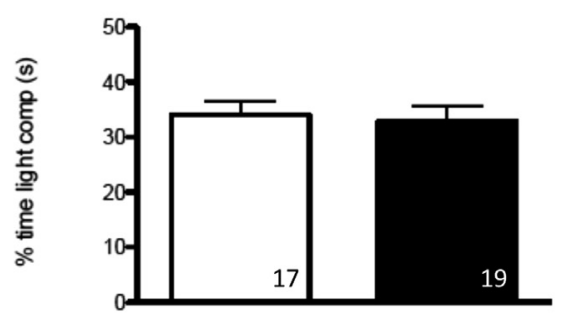

B

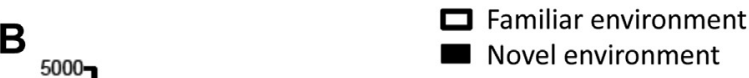

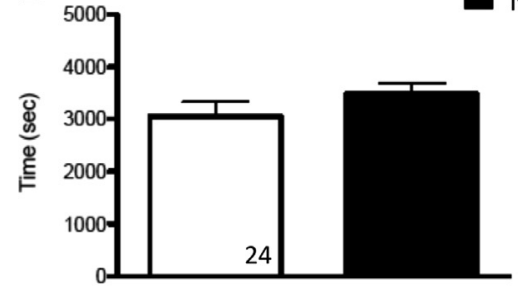

APP-WT

D

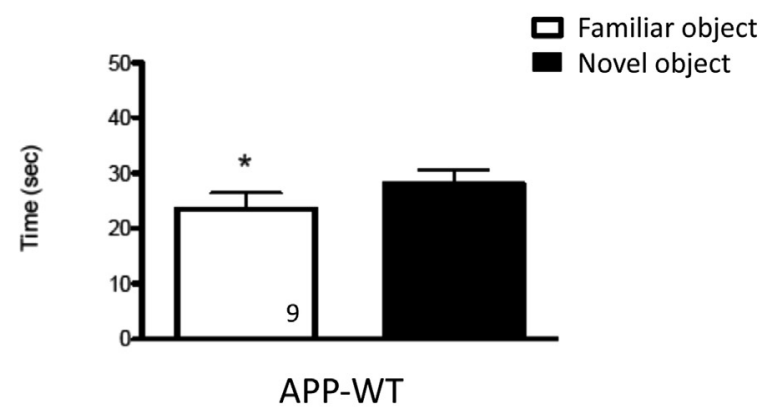

F

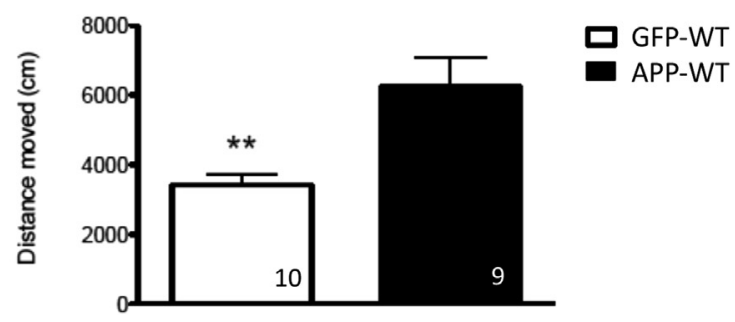

H

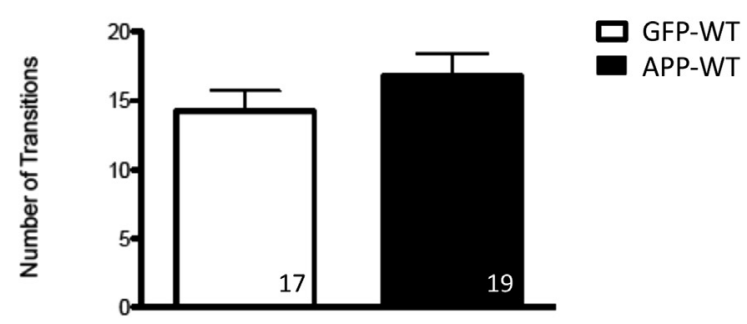

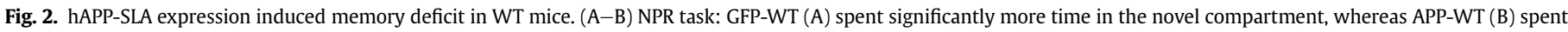

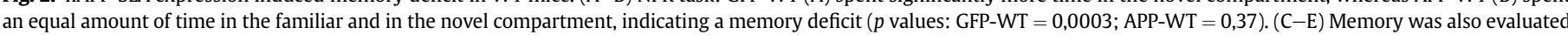

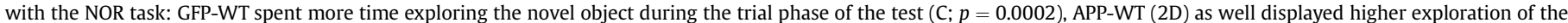

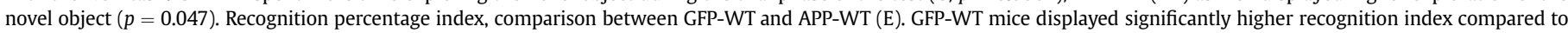

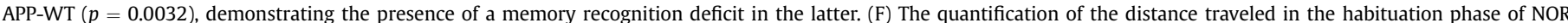

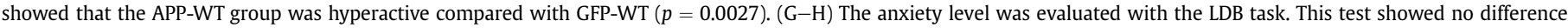

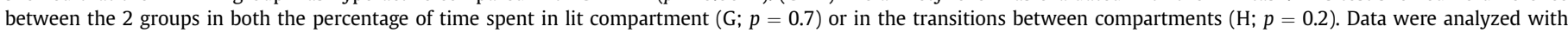

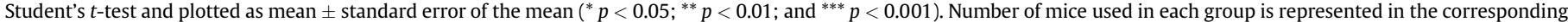

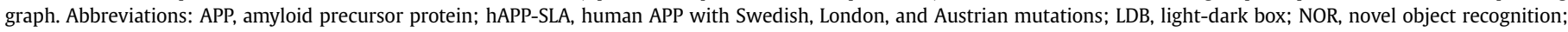
NPR, novel place recognition; WT, wild-type. 

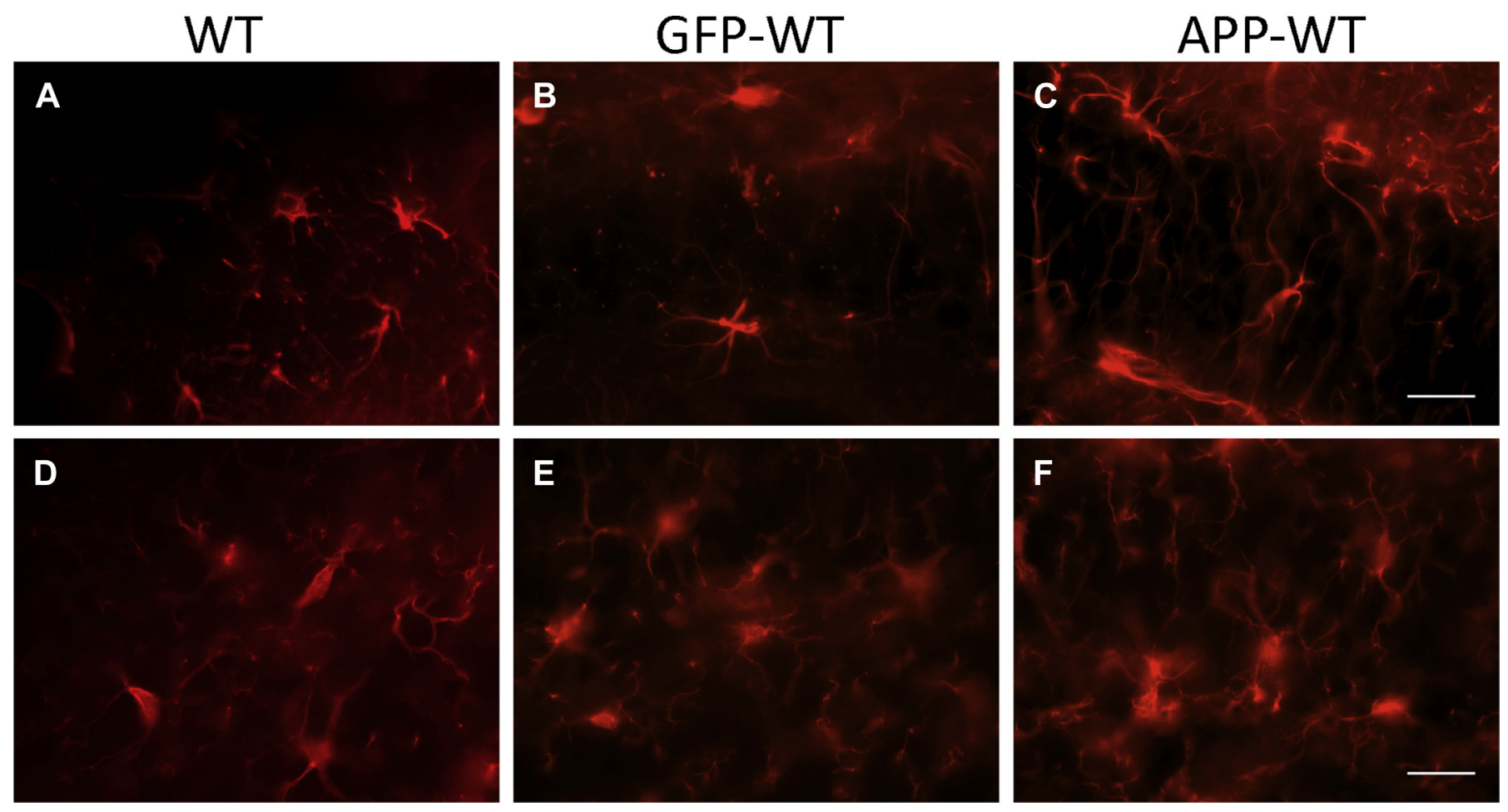

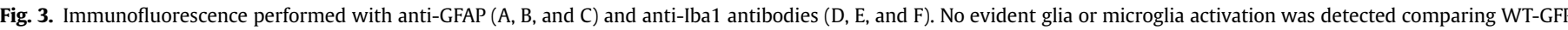

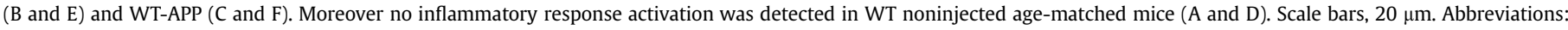
APP, amyloid precursor protein; WT, wild-type.

compartment for GFP-WT ( $p=0.0003$; Fig. 2A), whereas APP-WT did not show any preference for novel or familiar compartment $(p=0.3$; Fig. 2B). We then performed the NOR task at 15 months p.i. The analysis of total time of exploration during the test session showed that both GFP-WT and APP-WT spent significantly more time exploring the novel object $(p=0.0002$ and $p=0.047$, respectively; Fig. $2 \mathrm{C}$ and $\mathrm{D}$, respectively). However, the analysis of the recognition percentage for the same set of data showed that GFP-WT spent significantly more time exploring the novel object compared with APP-WT ( $p=0.0032$; Fig. 2E), suggesting the presence of a memory deficit in the APP-WT group. The locomotor behavior during the NOR habituation phase was measured by the total distance traveled: APP-WT showed higher locomotor activity compared with GFP-WT ( $p=0.0027$; Fig. 2F). We finally measured anxiety levels using the LDB paradigm. No differences were observed between both groups for the index of time spent in the lit compartment ( $p=0.7$ ) as well as for the number of transitions ( $p=$ 0.2 ; Fig. $2 \mathrm{G}-\mathrm{H}$ ). Hence, the transduction of hAPP-SLA in DG induces recognition memory deficits as supported by NPR and NOR tasks. We performed GFAP and Iba1 staining on WT-APP, WT-GFP, and WT noninjected mice to investigate whether or not the behavioral deficit we observed could be driven by neuroinflammation. We did not detect any glia or microglia activation in WT-APP (Fig. 3C and F) compared with WT-GFP (Fig. 3B and E), meaning that the neuroinflammation does not play a role in the memory deficit we observed. In addition, viral transduction did not induce any neuroinflammation, as shown in WT noninjected mice (Fig. 3A and D).

\section{3. $\beta 2 \mathrm{KO}$ mice are protected from hAPP-SLA induced memory impairment}

To address the potential role of nAChR subunits in the memory impairment observed in APP-WT, we delivered hAPP-SLA into the
DG of KO mice for $\beta 2$ or $\alpha 7$ subunits. In the NPR task ( 7 months p.i.), the GFP- $\beta 2$ spent significantly more time exploring the novel compartment ( $p=0.003$; Fig. $4 \mathrm{~A})$, as well as APP- $\beta 2(p=0.017$; Fig. 4B). Similarly, in the NOR task (15 months p.i.), both the GFP- $\beta 2$ and the APP- $\beta 2$ displayed higher exploration of the novel object ( $p<0.0001$ and $p=0.0001$, respectively; Fig. 4C and D), with no differences between the 2 groups in the recognition index ( $p=0.7$; Fig. 4E), meaning that $\beta 2$ mice injected with hAPP-SLA did not exhibit the recognition memory deficit observed in APP-WT. The analysis of the locomotion during the NOR habituation phase showed no differences between GFP- $\beta 2$ and APP- $\beta 2$ ( $p=0.2$; Fig. 4F). The LDB test showed no differences in anxiety levels measured as total time spent in the lit compartment $(p=0.52)$ and number of transitions ( $p=0.17$ ) between the APP- $\beta 2$ and the GFP$\beta 2$ (Fig. $4 \mathrm{G}-\mathrm{H}$ ). The hAPP-SLA transduction in DG did not induce a memory deficit in $\beta 2 \mathrm{KO}$, meaning that the $A \beta / \beta 2-n A C h R$ interaction is required to drive the memory deficit in this model.

\section{4. $n A C h R \alpha 7$ KO mice display memory impairment independently of hAPP expression}

The involvement of the $\alpha 7 \mathrm{nAChR}$ subunit in AD pathology had been investigated in previous studies that obtained conflicting results (Dziewczapolski et al., 2009; Hernandez et al., 2010, reviewed in). At 7 months p.i., both GFP- $\alpha 7$ ( $p=0.9$; Fig. $5 \mathrm{~A})$ and APP- $\alpha 7$ groups $(p=0.3$; Fig. $5 \mathrm{~B})$ displayed a memory deficit in the NPR task. Indeed, in our experimental conditions, there was no difference in the exploration of the novel or familiar compartment for GFP- $\alpha 7$ and APP- $\alpha 7$. We then tested age-matched noninjected mice to determine whether the memory deficit was related to the viral transduction in this strain. Noninjected mice spent the same amount of time exploring novel and familiar compartments during the test session ( $p=0.6$; Fig. $5 \mathrm{C}$ ), 
A

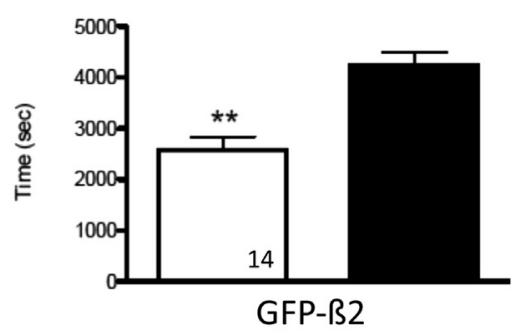

C

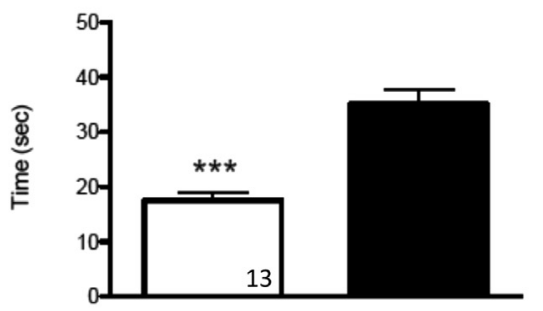

GFP-ß2

E

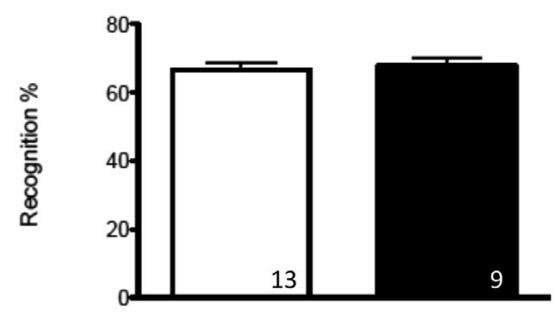

G

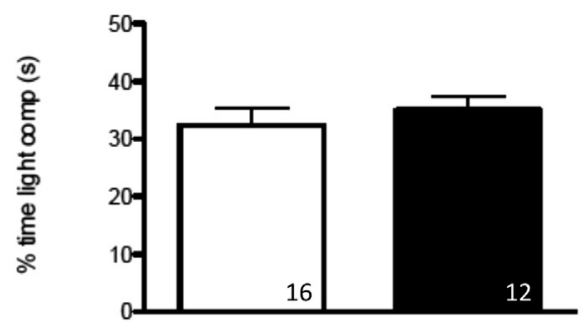

B

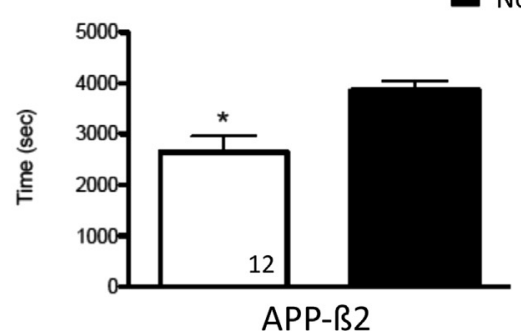

D

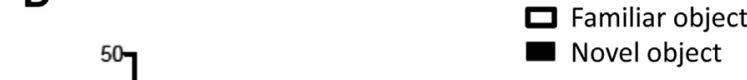

Familiar environment

Novel environment

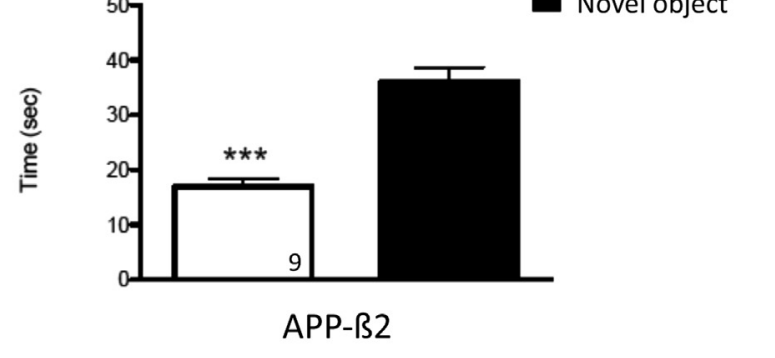

$\mathbf{F}$

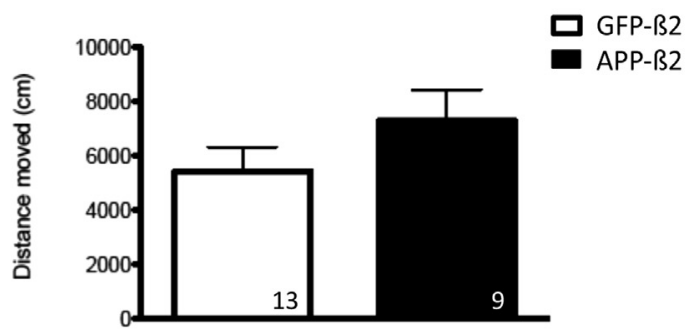

H

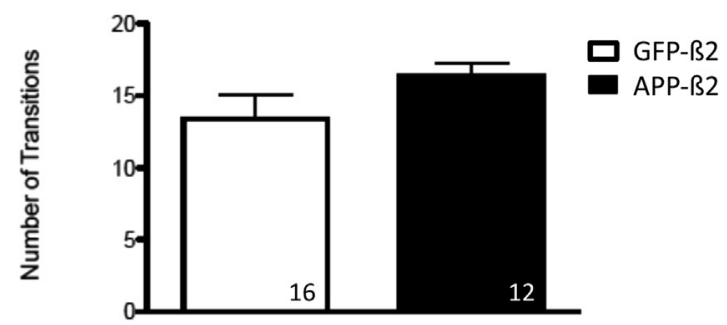

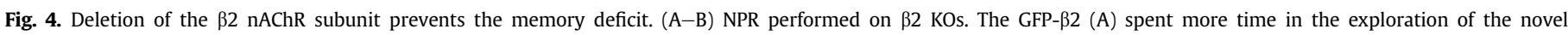

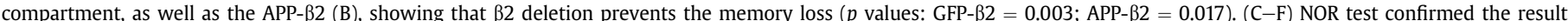

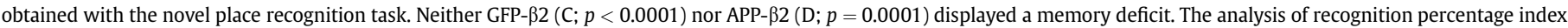

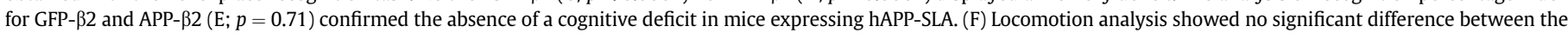

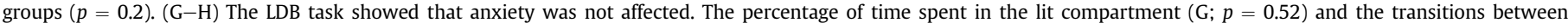

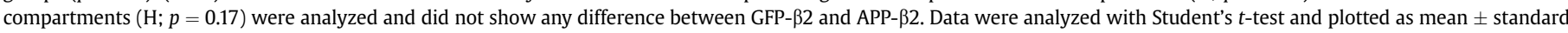

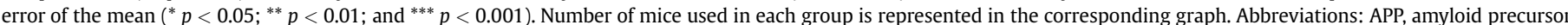

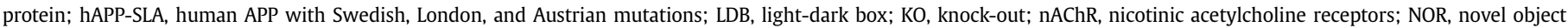
recognition; NPR, novel place recognition.

confirming the presence of a constitutive recognition memory deficit in age-matched $\alpha 7 \mathrm{KO}$ mice. In the NOR task (15 months p.i.) as well, both GFP- $\alpha 7$ and APP- $\alpha 7$ displayed a cognitive impairment (Fig. 5D-E). The analysis of the total exploration time during the NOR task showed that GFP- $\alpha 7$ spent similar time exploring the familiar and the novel objects ( $p=0.76$; Fig. 5D), whereas APP- $\alpha 7$ spent significantly more time exploring the novel object compared with the familiar one ( $p=0.01$; Fig. $5 \mathrm{E})$. Yet, the analysis of the recognition index showed no difference between GFP- $\alpha 7$ and APP- $\alpha 7$ (Fig. 5F). We found no difference in locomotor activity between the 2 groups ( $p=0.29$; Fig. $5 \mathrm{G}$ ). The LDB test revealed no difference between GFP- $\alpha 7$ and APP- $\alpha 7$ in the percentage of time spent in the lit compartment $(p=0.6$; Fig. $5 \mathrm{H}$ ), whereas the test showed higher number of transitions in APP- $\alpha 7$ compared with GFP- $\alpha 7$ ( $p=0.01$; Fig. 5I). Because the $\alpha 7$ KO had a memory deficit independent of hAPP-SLA expression, we could not draw any conclusion on the role of $\alpha 7$ in the memory deficit observed. However, we identify a possible role of the $\alpha 7$ subunit in the normal aging process that should be further investigated. 
A

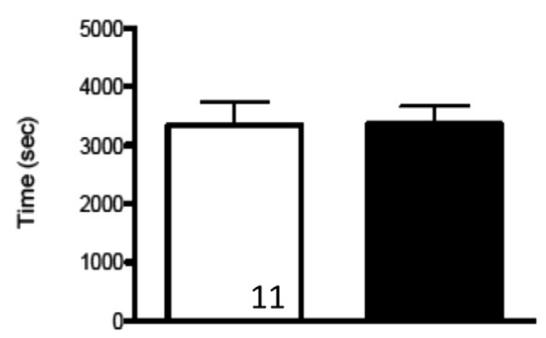

GFP- $\alpha 7$
B

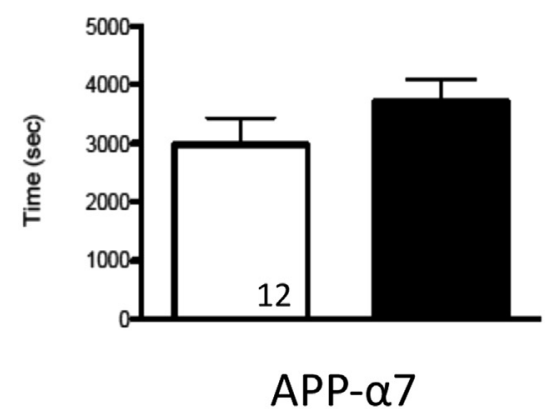

E

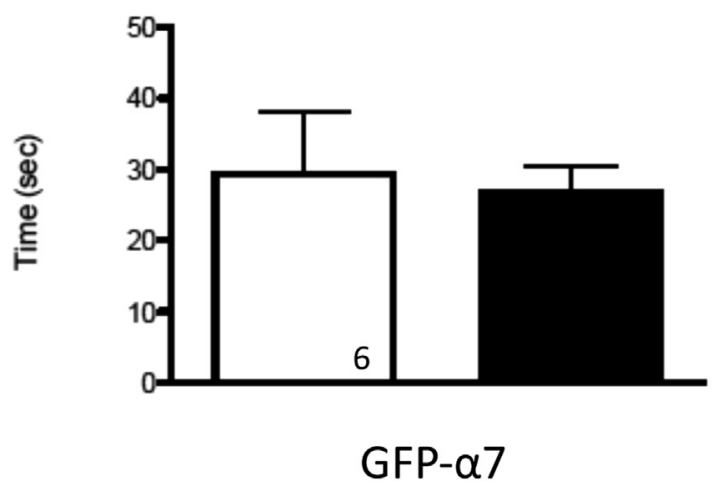

F

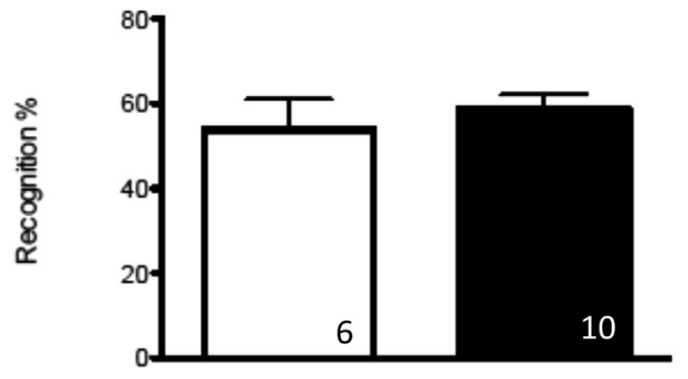

H

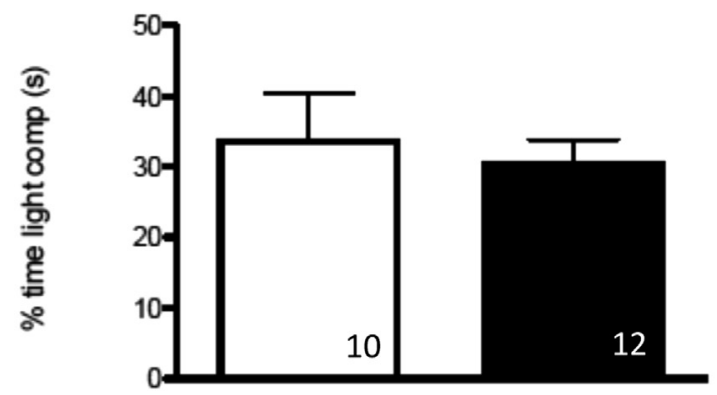

G

\section{I}

C

Familiar environment

Novel environment

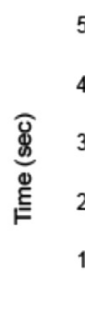

\section{$\alpha 7 \mathrm{KO}$}

Familiar object

Novel object

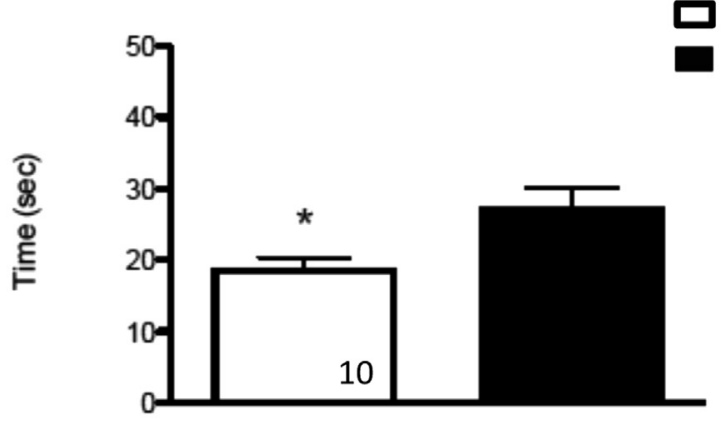

APP- $\alpha 7$

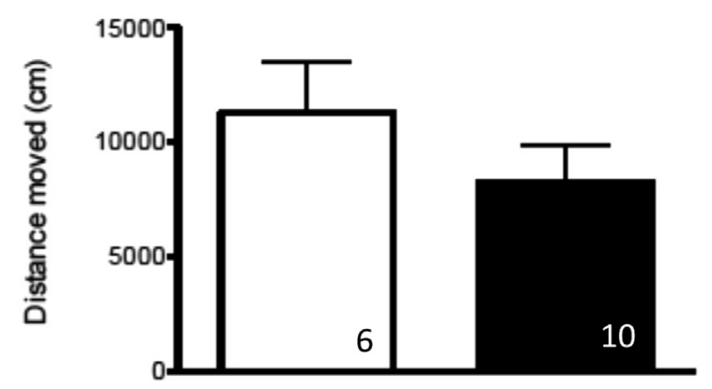

GFP- $\alpha 7$

APP- $\alpha 7$

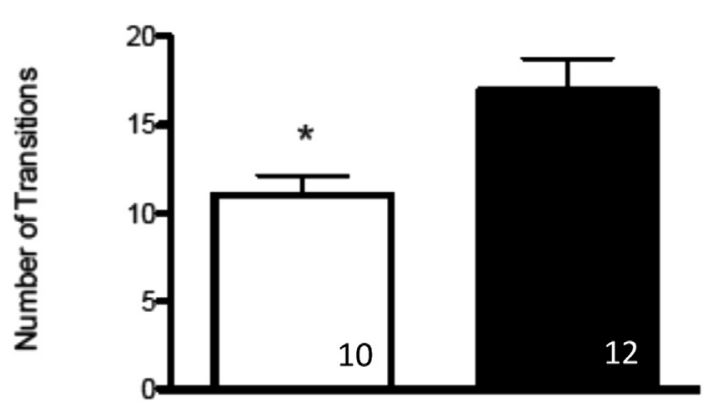

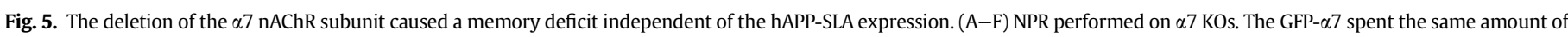

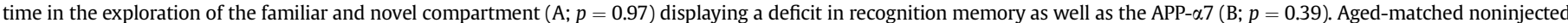

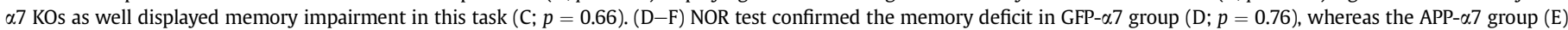

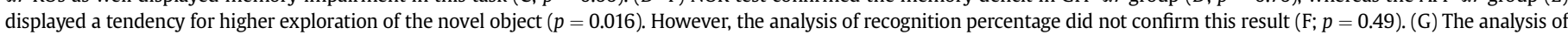

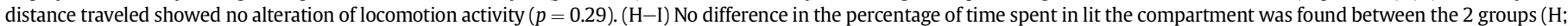

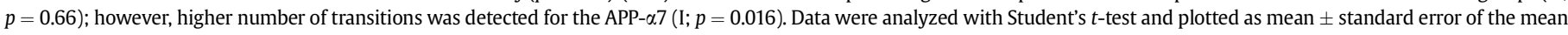

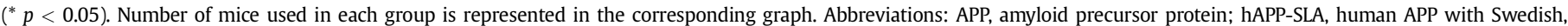
London, and Austrian mutations; KO, knock-out; nAChR, nicotinic acetylcholine receptors; NOR, novel object recognition; NPR, novel place recognition. 


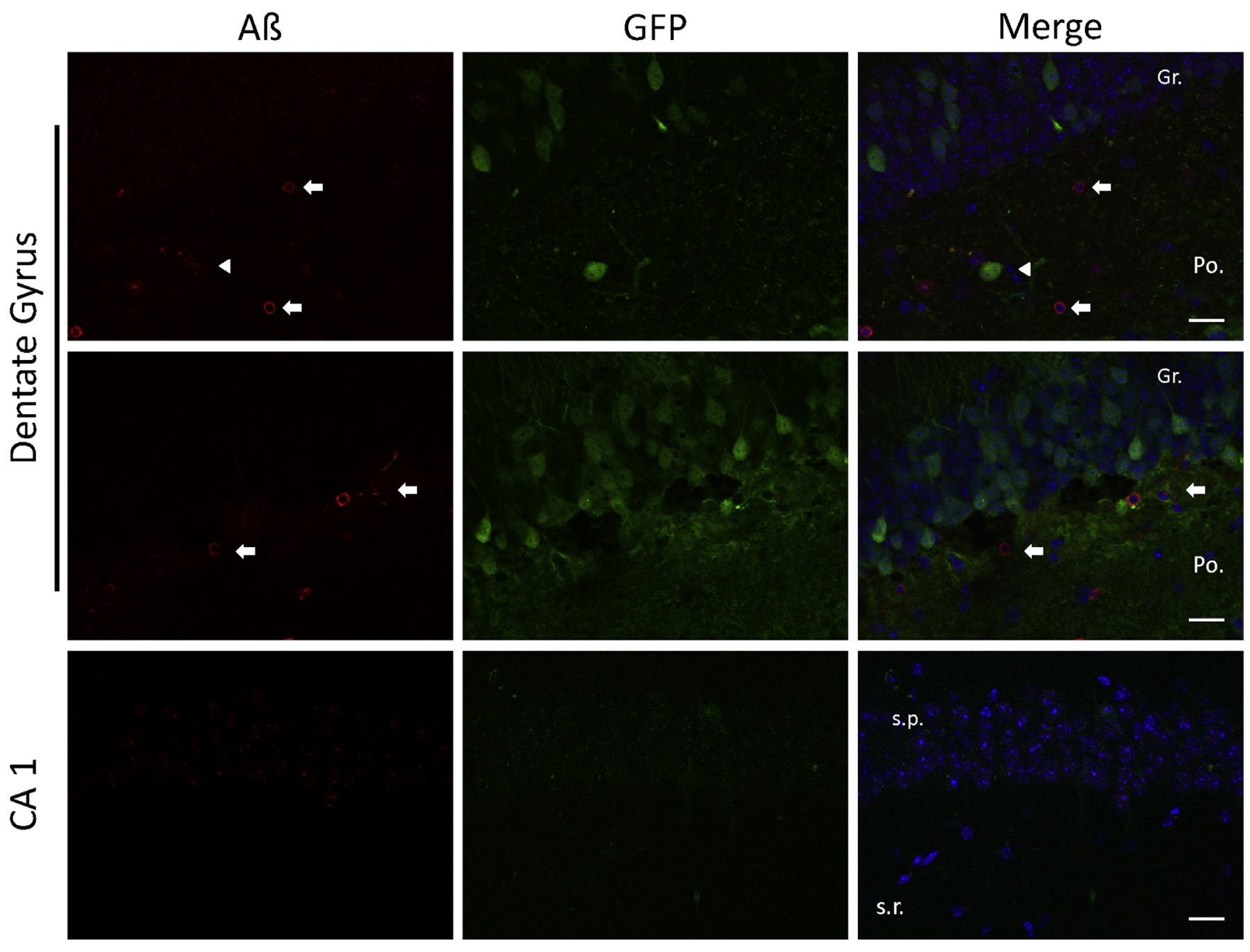

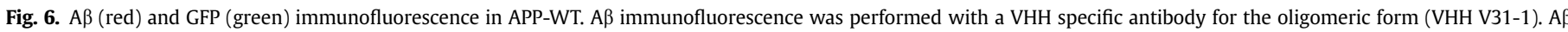

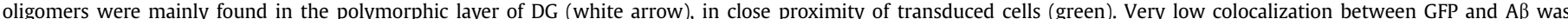

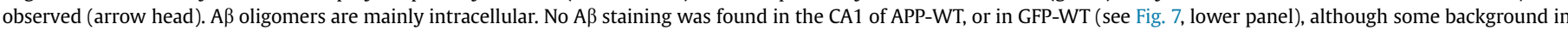

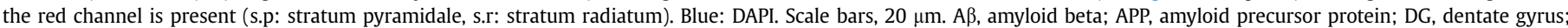

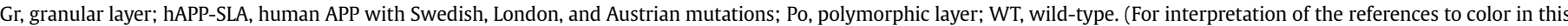
figure legend, the reader is referred to the Web version of this article.)

\subsection{The expression of hAPP-SLA drives synthesis and intracellular accumulation of $A \beta$}

Several studies showed that in AD animal models, the appearance of the cognitive deficits precedes plaque deposition (Casas et al., 2004; Gouras et al., 2000; Kumar et al., 2013; Wirths et al., 2004). We investigated whether the transduction of hAPP-SLA was able to drive $A \beta$ accumulation in our model. The presence of oligomeric $A \beta$ in APP-WT was confirmed with the antibody $\mathrm{VHH}$ 31-1, specific for oligomeric forms of $A \beta$ (Lafaye et al., 2009). $A \beta$ was mainly found in the polymorphic layer of the DG (Fig. 6, arrows). Oligomeric $A \beta$ was due to hAPP-SLA expression because $A \beta$ oligomers were not observed in CA1, where there was no viral transduction (Fig. 6). A $\beta$ intracellular accumulation in DG polymorphic layer was also confirmed with the rat monoclonal 7H3D6 antibody, also specific for oligomeric $A \beta$ (Kumar et al., 2013) (Fig. 7, arrow). The antigen retrieval protocol required for this staining resulted in higher background noise and lower GFP signal. The signal in granular cell layer of WT-GFP and WT-APP was considered as background (Fig. 7, arrow head).
We then investigated the presence of $A \beta$ aggregates in the hippocampus of APP- $\beta 2$ and APP- $\alpha$ 7. In APP- $\beta 2$, a positive staining for $A \beta$ oligomers using the VHH 31-1 antibody was found (Fig. 8, arrows). We observed intracellular $A \beta$ staining in the polymorphic layer of the DG that was absent in GFP- $\beta 2$ (Fig. 8). Immunofluorescence performed with VHH 31-1 on brain slices of APP- $\alpha 7$ mice also showed intracellular $A \beta$ oligomers in the polymorphic layer (Fig. 8, arrows), whereas GFP- $\alpha 7$ mice did not show any $A \beta$ oligomers.

\section{Discussion}

We have developed a novel mouse model based on the lentiviral delivery of a hAPP-SLA expressing vector to investigate the implication of substructures of the hippocampus in amyloid pathology. The AD rodent models commonly used are transgenic organisms that constitutively express high levels of mutated hAPP in the whole brain, and throughout prenatal and postnatal development. However, in some models, the use of the Thy 1 promoter allows a postdevelopmental expression of APP (e.g., Oakley et al., 2006; 

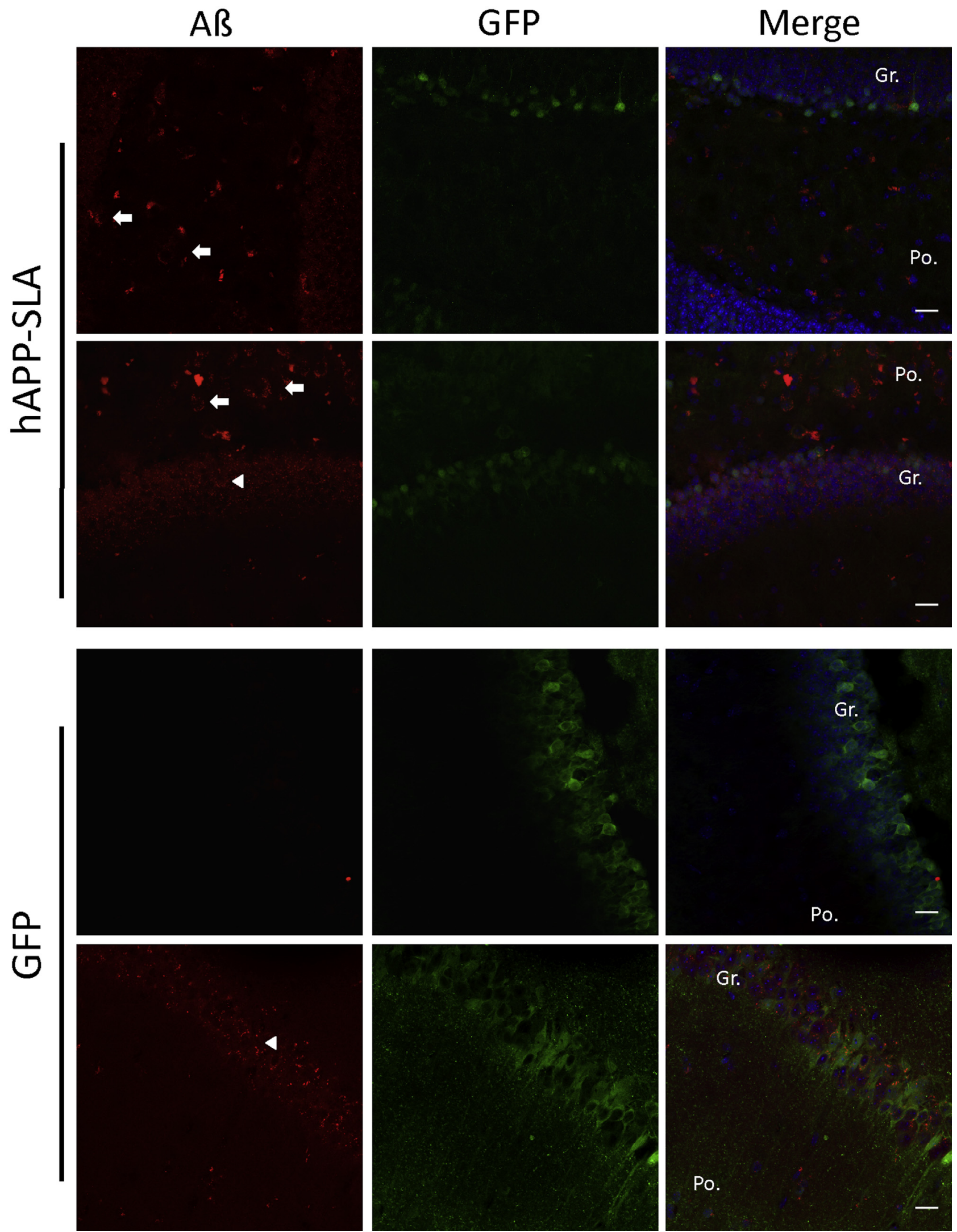

Fig. 7. Immunofluorescence in APP-WT (upper panel) and GFP-WT (lower panel) performed with the rat monoclonal 7H3D6 antibody. Intracellular A $\beta$ was detected in the polymorphic layer of DG (white arrow) of WT-APP (upper panel), whereas it was absent in WT-GFP (lower panel). Some background in the granular layer of WT-GFP (arrow head) was detected and considered nonspecific. Red: A $\beta$, green: GFP, and blue: DAPI. Scale bars, $20 \mu \mathrm{m}$. Abbreviations: AB, amyloid beta; APP, amyloid precursor protein; DG, dentate gyrus; Gr, granular layer; hAPP-SLA, human APP with Swedish, London, and Austrian mutations; Po, polymorphic layer; WT, wild-type. (For interpretation of the references to color in this figure legend, the reader is referred to the Web version of this article.) 


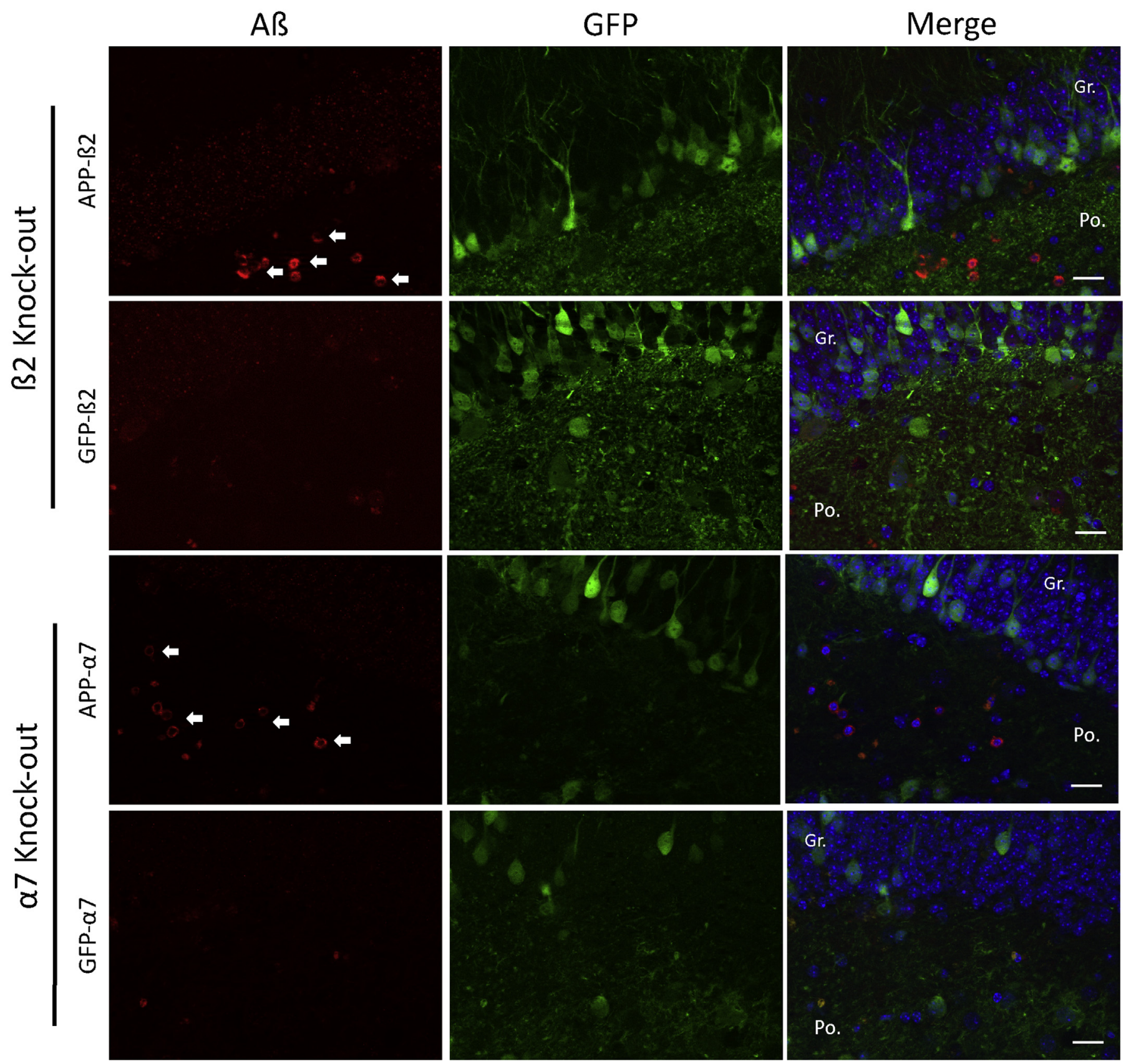

Fig. 8. Immunofluorescence in $\beta 2$ and $\alpha 7 \mathrm{KO}$ mice. A $\beta$ intracellular staining (red) was found only in DG of APP- $\beta 2$ and APP- $\alpha 7$ and absent in GFP- $\beta 2$ or GFP- $\alpha 7$. A $\beta$ positive cells were localized in the polymorphic layer of the DG in both $\beta 2$ and $\alpha 7$ KO mice (white arrow). Blue: DAPI. Scale bars, $20 \mu \mathrm{m}$. Abbreviations: A $\beta$, amyloid beta; APP, amyloid precursor protein; DG, dentate gyrus; Gr, granular layer; KO, knock-out; Po, polymorphic layer. (For interpretation of the references to color in this figure legend, the reader is referred to the Web version of this article.)

Oddo et al., 2003), whereas a better temporal regulation of APP expression is obtained with a TeTOn model (Jankowsky et al., 2005), in which APP is located downstream of a tetracycline-responsive promoter. However, none of these models allow the accurate expression of APP in a specific brain structure. Thus, the main advantage of our model is to produce $A \beta$ in the adult brain and in specific targeted area.

The lentiviral transfer vector we generated expresses the sequence of human APP harboring 3 pathogenic mutations, the Swedish double mutation (KM670/671NL) (Mullan et al., 1992), the London mutation (V717I) (Goate et al., 1991), and the Austrian mutation (T714I) (Kumar-Singh et al., 2000). These 3 mutations were chosen for their close proximity to the secretase cleavage sites ( $\beta$-secretase for the Swedish and $\gamma$-secretase for London and Austrian) and were reported to increase $A \beta$ synthesis (Goate et al., 1991; Kumar-Singh et al., 2000; Mullan et al., 1992). The technology of lentiviral transduction was already used to generate models to study hAPP processing in vitro (Shaughnessy et al., 2005). In vivo models based on adeno-associated virus (AVV) vectors had also previously been generated (Gong et al., 2006; Jaworski et al., 2009; Lawlor et al., 2007; Nishimura et al., 1998). In the present work, we chose a lentiviral vector because its cloning capacity is bigger compared to AAV. This allowed the insertion of the IRES-GFP sequence for an easy and rapid analysis of viral transduction 
efficiency and diffusion in the targeted area. We were able to infect specific subregions of the hippocampus, like the CA1 and CA3 pyramidal cell regions (data not shown), and the DG (Fig. 1D).

Because memory is one of the first human cognitive functions affected in AD patients (Hildebrandt et al., 2013), we decided to target the hippocampus, and in particular the DG, which is a key region for memory formation (Morris, 2006; Squire et al., 2007). In addition, amyloid deposition in the hippocampus of $\mathrm{AD}$ patients was previously established (Braak and Braak, 1991). We quantified fluorescence intensity outside the targeted area and found 3-fold lower fluorescence intensity in CA1 and CA3 areas compared to DG, meaning that most transduced cells are located in the selected area. There is probably a diffusion of the vector solution from the needle to CA1 at the moment of the injection (Fig. 1D, arrow head), whereas the fluorescence in CA3 most probably originates from the projection of the DG through the mossy fiber pathway (Fig. 1D, arrow). We can conclude that the DG was efficiently targeted. Moreover, a single injection led to good diffusion within the hippocampus (Fig. 1D) and was able to induce a recognition memory deficit together with the accumulation of intracellular oligomeric $A \beta$, whereas no sign of inflammation was detected (Fig. 3). These features are all associated with early-stage AD pathology (Kumar et al., 2013). For A $\beta$ staining, we used a VHH derived from alpaca antibodies (Hamers-Casterman et al., 1993) specific for oligomeric $A \beta$. VHH specifically recognizes low-molecular-weight species of $A \beta$ (monomers, dimers, trimers, tetramers, and 12-mers, but not the fibril form), mostly intraneuronal (Lafaye et al., 2009). In APP-WT, $A \beta$ deposition was further demonstrated by the use of the rat monoclonal 7H3D6 antibody (Kumar et al., 2013), specific for monomeric and oligomeric $A \beta$ (Fig. 7).

Little colocalization between GFP positive neurons and $A \beta$ was found (Fig. 6, arrow head). We hypothesize that once $A \beta$ is secreted from the hAPP-SLA-expressing cell (GFP positives cells), it is then recaptured by the surroundings cells. However, $A \beta$ synthesis was strictly confined to the lentivirus injection site because in CA1, where there was no hAPP-SLA expression, $A \beta$ oligomers were absent (Fig. 6), as in GFP-injected mice (Fig. 7, lower panel, and Fig. 8). Thus, we have generated a novel model displaying memory deficit and $A \beta$ oligomerization in which it is possible to study changes induced by $A \beta$ deposition in a restricted brain area.

The major advantage of our methodology is that it is applicable to every animal model and strain. We decided to use it to study the implication of $\mathrm{nAChRs}$ in $\mathrm{AD}$-like pathology. In this work, we investigated the role of $\alpha 7$ and $\beta 2 \mathrm{nAChR}$ subunits. Although $\alpha 7$ had been shown to physically interact with $A \beta$ (Wang et al., 2000a,b), only a functional link in vitro between $\beta 2$ and $A \beta$ was reported, as $\mathrm{A} \beta$ was shown to inhibit $\beta 22^{*}$-nAChR currents (Lamb et al., 2005; Pandya and Yakel, 2011). Our data strongly suggest that the lack of the $\beta 2$ subunit prevents $A \beta$-induced memory loss because $\beta 2 \mathrm{KO}$ animals are protected from the recognition memory impairment induced by APP-SLA expression in control mice. To date, this is the first in vivo demonstration of a role for the $\beta 2$ subunit in $\mathrm{A} \beta$-induced toxicity.

Previous studies extensively reported degeneration of the cholinergic system in AD, particularly the basal forebrain cholinergic cells that innervate the neocortex and hippocampus. Their degeneration in $\mathrm{AD}$ is associated with reduced levels of pre and postsynaptic cholinergic markers in the cortex, hippocampus, and amygdala.

Electrophysiological and binding studies demonstrated that nAChRs are expressed in discrete parts of the hippocampus. Notably, in the DG, both $\alpha 7$ and $\beta 2$ subunits are expressed in the molecular layer, in particular, in GABAergic interneurons (Frazier et al., 2003; Gahring and Rogers, 2008; Son and Winzer-Serhan, 2008), and $\alpha 7$ nAChRs were reported to induce LTP in DG
(Matsuyama et al., 2000). No nicotinic responses have been identified in dentate granule cells (Jones and Yakel, 1997), but hippocampal neurogenesis is altered in $\beta 2 \mathrm{KO}$ mice (Harrist et al., 2004). Liu et al (Liu et al., 2009) recently postulated the existence of an $\alpha 7 \beta 2 \mathrm{nAChR}$ heteromer in basal forebrain cholinergic neurons, that is also expressed in CA1 interneurons. This novel nAChR subtype is characterized by a high sensitivity to $A \beta$ inhibition (Liu et al., 2012), and this interaction could be responsible for the memory deficit observed in AD. It has been reported that both $\beta 2$ and $\alpha 7$ subunits are important for working memory. Local infusion of $\alpha 7 \mathrm{nAChR}$ and $\alpha 4 \beta 2$ nAChR antagonist (MLA and DH $\beta E$, respectively) in ventral hippocampus induces working memory impairments (Felix and Levin, 1997; Levin et al., 2002). Thus, nAChRs are key regulatory elements of hippocampal circuit activity (Frazier et al., 2003; OrrUrtreger et al., 1997). We hypothesize that nAChR-A $\beta$ interaction could alter the electrophysiological activity of interneurons in DG. $A \beta$ inhibition of nAChRs could interfere with their regulatory function, leading to neuronal hyperactivity in the hippocampus and subsequent memory impairment. In our model, the absence of the $\beta 2$ subunit ( $\beta 2 \mathrm{KO}$ ) could be protective for the neurons by preventing a toxic $n A C h R-A \beta$ interaction.

$\beta 2$ KO mice have previously been characterized. This line showed lack of nicotine-induced striatal dopamine release, decreased locomotor activity after habituation (Picciotto et al., 1998, 1995), and altered exploratory behavior (Avale et al., 2008; Besson et al., 2007; Bourgeois et al., 2012; Maskos et al., 2005). In addition, $\beta 2$ KO showed increased neurodegeneration during aging (Picciotto et al., 2000; Zoli et al., 1999). Contradictory results exist about memory impairment in $\beta 2 \mathrm{KO}$ mice Wiklund et al. (2009) did not identify any impairment. On the other hand, some authors found spatial learning deficits (Levin et al., 2009). However, this may be more related to attention deficits (Guillem et al., 2011).

Previous in vivo work attempted to dissect the role of $\alpha 7 \mathrm{nAChRs}$ in AD (Dziewczapolski et al., 2009; Hernandez et al., 2010). In both studies, AD mouse models were crossed with $\alpha 7$ nAChR nullmutants. However, these studies came to opposite conclusions, improvement, and worsening, respectively, of AD-associated phenotypes, such as memory and synaptic deficits. In our experimental conditions, APP- $\alpha 7$ displayed an inherent memory deficit that was independent of injection, making it impossible to conclude concerning the effect of $A \beta$ accumulation in this line. The $\alpha 7 \mathrm{KO}$ line had previously been characterized by Paylor et al. (Paylor et al., 1998). A large panel of behaviors like motor and sensory responses, locomotor activity in the open field, motor coordination, and spatial memory were investigated. These authors found no difference between $\alpha 7 \mathrm{KO}$ and WT mice. More recent studies showed an attention deficit in the 5-choice serial reaction time task, but no memory impairment, in $\alpha 7 \mathrm{KO}$ mice (Hoyle et al., 2006; Young et al., 2011, $2007,2004)$. However, we observed a memory deficit in old $\alpha 7$ KO mice (18 months at the end of the experiments). It is possible that the aging process exacerbates memory impairment in $\alpha 7 \mathrm{KO}$. Indeed, it was shown that hippocampal LTP is impaired in old $\alpha 7 \mathrm{KO}$ and that this alteration was directly linked to aging (Ma et al., 2014).

The cholinergic anti-inflammatory pathway is known to attenuate the inflammatory response and the progression of inflammatory diseases (Shi et al., 2009; Tracey, 2009). Initial studies suggested that the cholinergic system modulates inflammation via the $\alpha 7 \mathrm{nAChR}$. However, a recent study demonstrated the role of $\alpha 4 \beta 2 \mathrm{nAChR}$ in the activation of intestinal macrophages (van der Zanden et al., 2009; Wang et al., 2003; ). Despite the fact that we excluded the activation of an immune response in APP-WT (Fig. 3), we cannot completely exclude an alteration in inflammatory response in $\alpha 7 \mathrm{KO}$ and $\beta 2 \mathrm{KO}$ mice. This could play a role in the toxicity induced by $A \beta$ oligomers and delay the onset of the behavioral deficit in KOs. The exact mechanism through which 
$A \beta$-nAChR interaction leads to memory deficit needs to be further investigated.

\section{Conclusions}

In conclusion, we have developed a novel model to study the neural and behavioral consequences induced by localized $A \beta$ accumulation in adult mice that can be applied to every line and species, avoiding crossbreeding of transgenic lines. In addition, this method could be very useful to investigate region-specific vulnerability in $A D$ linked to $A \beta$ deposition. Moreover, this can be a powerful tool to investigate the "prion" hypothesis of AD (Frost and Diamond, 2010), according to which there is a progressive spread of $A \beta$ in the course of AD across several cerebral pathways. Indeed, the model we developed allows to follow the accumulation of amyloid deposition from 1 targeted brain structure to connected areas. To date, this is the first mouse model based on a lentiviral vector that was shown to induce a cognitive deficit in relationship to ADrelated histopathological changes.

\section{Disclosure statement}

The authors have no conflicts of interest to disclose.

\section{Acknowledgements}

This work was supported by EU FP7 ITN « BrainTrain », Fondation pour la Recherche Médicale FRM (grant number, DPA20140629803), DARRI grant PasteurInnov 2012, CNRS UMR 3571, DIM Région Ile de France, and Fondation Gilbert Lagrue. The authors would like to thank Stéphanie Pons for constant assistance throughout the course of this work, Sathish Kumar, Jochen Walter, and Pierre Lafaye for the gift of antibodies, and Céline Héraud and Chantal Mathis for perfused brains.

\section{References}

Auld, D.S., Kornecook, T.J., Bastianetto, S., Quirion, R., 2002. Alzheimer's disease and the basal forebrain cholinergic system: relations to $\beta$-amyloid peptides, cognition, and treatment strategies. Prog. Neurobiol. 68, 209-245.

Avale, M.E., Faure, P., Pons, S., Robledo, P., Deltheil, T., David, D.J., Gardier, A.M., Maldonado, R., Granon, S., Changeux, J.-P., Maskos, U., 2008. Interplay of beta2* nicotinic receptors and dopamine pathways in the control of spontaneous locomotion. Proc. Natl. Acad. Sci. U. S. A 105, 15991-15996.

Besson, M., Granon, S., Mameli-Engvall, M., Cloëz-Tayarani, I., Maubourguet, N., Cormier, A., Cazala, P., David, V., Changeux, J.-P., Faure, P., 2007. Long-term effects of chronic nicotine exposure on brain nicotinic receptors. Proc. Natl. Acad. Sci. U. S. A 104, 8155-8160.

Bourgeois, J.-P., Meas-Yeadid, V., Lesourd, A.-M., Faure, P., Pons, S., Maskos, U., Changeux, J.-P., Olivo-Marin, J.-C., Granon, S., 2012. Modulation of the mouse prefrontal cortex activation by neuronal nicotinic receptors during novelty exploration but not by exploration of a familiar environment. Cereb. Cortex 22, 1007-1015.

Braak, H., Braak, E., 1991. Neuropathological stageing of Alzheimer-related changes. Acta Neuropathol. (Berl.) 82, 239-259.

Casas, C., Sergeant, N., Itier, J.-M., Blanchard, V., Wirths, O., van der Kolk, N., Vingtdeux, V., van de Steeg, E., Ret, G., Canton, T., Drobecq, H., Clark, A., Bonici, B., Delacourte, A., Benavides, J., Schmitz, C., Tremp, G., Bayer, T.A., Benoit, P., Pradier, L., 2004. Massive CA1/2 neuronal loss with intraneuronal and N-Terminal truncated A 342 accumulation in a novel Alzheimer transgenic model. Am. J. Pathol. 165, 1289-1300.

de Chaumont, F., Dallongeville, S., Chenouard, N., Hervé, N., Pop, S., Provoost, T., Meas-Yedid, V., Pankajakshan, P., Lecomte, T., Le Montagner, Y., Lagache, T., Dufour, A., Olivo-Marin, J.-C., 2012. Icy: an open bioimage informatics platform for extended reproducible research. Nat. Methods 9, 690-696.

Dull, T., Zufferey, R., Kelly, M., Mandel, R.J., Nguyen, M., Trono, D., Naldini, L., 1998. A third-generation lentivirus vector with a conditional packaging system. J. Virol. 72, 8463-8471.

Dziewczapolski, G., Glogowski, C.M., Masliah, E., Heinemann, S.F., 2009. Deletion of the $\alpha 7$ nicotinic acetylcholine receptor gene improves cognitive deficits and synaptic pathology in a mouse model of Alzheimer's disease. J. Neurosci. 29, 8805-8815.
Epis, R., Gardoni, F., Marcello, E., Genazzani, A., Canonico, P.L., Di Luca, M., 2010 Searching for new animal models of Alzheimer's disease. Eur. J. Pharmacol. 626 57-63.

Felix, R., Levin, E.D., 1997. Nicotinic antagonist administration into the ventral hippocampus and spatial working memory in rats. Neuroscience 81, 1009-1017.

Frazier, C.J., Strowbridge, B.W., Papke, R.L., 2003. Nicotinic receptors on local circuit neurons in dentate gyrus: a potential role in regulation of granule cell excitability. J. Neurophysiol. 89, 3018-3028.

Frost, B., Diamond, M.I., 2010. Prion-like mechanisms in neurodegenerative diseases. Nat. Rev. Neurosci. 11, 155-159.

Gahring, L.C., Rogers, S.W., 2008. Nicotinic acetylcholine receptor expression in the hippocampus of 27 mouse strains reveals novel inhibitory circuitry. Hippocampus 18, 737-749.

Goate, A., Chartier-Harlin, M.-C., Mullan, M., Brown, J., Crawford, F., Fidani, L., Giuffra, L., Haynes, A., Irving, N., James, L., Mant, R., Newton, P., Rooke, K. Roques, P., Talbot, C., Pericak-Vance, M., Roses, A., Williamson, R., Rossor, M., Owen, M., Hardy, J., 1991. Segregation of a missense mutation in the amyloid precursor protein gene with familial Alzheimer's disease. Nature 349, 704-706.

Gong, Y., Meyer, E.M., Meyers, C.A., Klein, R.L., King, M.A., Hughes, J.A., 2006 Memory-related deficits following selective hippocampal expression of Swedish mutation amyloid precursor protein in the rat. Exp. Neurol. 200, 371-377.

Gotti, C., Moretti, M., Bohr, I., Ziabreva, I., Vailati, S., Longhi, R., Riganti, L., Gaimarri, A. McKeith, I.G., Perry, R.H., Aarsland, D., Larsen, J.P., Sher, E., Beattie, R., Clementi, F. Court, J.A., 2006. Selective nicotinic acetylcholine receptor subunit deficits identified in Alzheimer's disease, Parkinson's disease and dementia with Lewy bodies by immunoprecipitation. Neurobiol. Dis. 23, 481-489.

Gouras, G.K., Tsai, J., Naslund, J., Vincent, B., Edgar, M., Checler, F., Greenfield, J.P., Haroutunian, V., Buxbaum, J.D., Xu, H., Greengard, P., Relkin, N.R., 2000. Intraneuronal A 342 accumulation in human brain. Am. J. Pathol. 156, 15-20.

Guillem, K., Bloem, B., Poorthuis, R.B., Loos, M., Smit, A.B., Maskos, U., Spijker, S., Mansvelder, H.D., 2011. Nicotinic acetylcholine receptor $\beta 2$ subunits in the medial prefrontal cortex control attention. Science 333, 888-891.

Hamers-Casterman, C., Atarhouch, T., Muyldermans, S., Robinson, G., Hamers, C., Songa, E.B., Bendahman, N., Hamers, R., 1993. Naturally occurring antibodies devoid of light chains. Nature 363, 446-448.

Harrist, A., Beech, R.D., King, S.L., Zanardi, A., Cleary, M.A., Caldarone, B.J., Eisch, A. Zoli, M., Picciotto, M.R., 2004. Alteration of hippocampal cell proliferation in mice lacking the beta 2 subunit of the neuronal nicotinic acetylcholine receptor: Synapse 54, 200-206.

Hernandez, C.M., Kayed, R., Zheng, H., Sweatt, J.D., Dineley, K.T., 2010. Loss of $\alpha 7$ nicotinic receptors enhances $\beta$-amyloid oligomer accumulation, exacerbating early-stage cognitive decline and septohippocampal pathology in a mouse model of Alzheimer's disease. J. Neurosci. 30, 2442-2453.

Hildebrandt, H., Fink, F., Kastrup, A., Haupts, M., Eling, P., 2013. Cognitive profiles of patients with mild cognitive impairment or dementia in Alzheimer's or Parkinson's disease. Dement. Geriatr. Cogn. Dis. Extra 3, 102-112.

Hoyle, E., Genn, R.F., Fernandes, C., Stolerman, I.P., 2006. Impaired performance of alpha7 nicotinic receptor knockout mice in the five-choice serial reaction time task. Psychopharmacology (Berl.) 189, 211-223.

Jankowsky, J.L., Slunt, H.H., Gonzales, V., Savonenko, A.V., Wen, J.C., Jenkins, N.A. Copeland, N.G., Younkin, L.H., Lester, H.A., Younkin, S.G., Borchelt, D.R., 2005 Persistent amyloidosis following suppression of Abeta production in a transgenic model of Alzheimer disease. PLoS Med. 2, e355.

Jaworski, T., Dewachter, I., Lechat, B., Croes, S., Termont, A., Demedts, D. Borghgraef, P., Devijver, H., Filipkowski, R.K., Kaczmarek, L., Kügler, S., Van Leuven, F., 2009. AAV-Tau mediates pyramidal neurodegeneration by cell-cycle re-entry without neurofibrillary tangle formation in wild-type mice. PLoS One 4, e7280.

Jones, S., Yakel, J.L., 1997. Functional nicotinic ACh receptors on interneurones in the rat hippocampus. J. Physiol. 504 (Pt 3), 603-610.

Kumar, S., Wirths, O., Theil, S., Gerth, J., Bayer, T.A., Walter, J., 2013. Early intraneuronal accumulation and increased aggregation of phosphorylated Abeta in a mouse model of Alzheimer's disease. Acta Neuropathol. (Berl.) 125, 699-709.

Kumar-Singh, S., DeJonghe, C., Cruts, M., Kleinert, R., Wang, R., Mercken, M. Strooper, B.D., Vanderstichele, H., Löfgren, A., Vanderhoeven, I., Backhovens, H., Vanmechelen, E., Kroisel, P.M., Broeckhoven, C.V., 2000. Nonfibrillar diffuse amyloid deposition due to a $\gamma 42$-secretase site mutation points to an essential role for N-truncated A 342 in Alzheimer's disease. Hum. Mol. Genet. 9, 2589-2598.

Lafaye, P., Achour, I., England, P., Duyckaerts, C., Rougeon, F., 2009. Single-domain antibodies recognize selectively small oligomeric forms of amyloid $\beta$, prevent $\mathrm{A} \beta$-induced neurotoxicity and inhibit fibril formation. Mol. Immunol. 46, 695-704.

LaFerla, F.M., Green, K.N., 2012. Animal models of Alzheimer disease. Cold Spring Harb. Perspect. Med. 2:a006320, 1-13.

Lamb, P.W., Melton, M.A., Yakel, J.L., 2005. Inhibition of neuronal nicotinic acetylcholine receptor channels expressed in Xenopus oocytes by beta-amyloid1-42 peptide. J. Mol. Neurosci. 27, 13-21.

Lawlor, P.A., Bland, R.J., Das, P., Price, R.W., Holloway, V., Smithson, L., Dicker, B.L., During, M.J., Young, D., Golde, T.E., 2007. Novel rat Alzheimer's disease models based on AAV-mediated gene transfer to selectively increase hippocampal A $\beta$ levels. Mol. Neurodegener. 2, 11

Levin, E.D., Bradley, A., Addy, N., Sigurani, N., 2002. Hippocampal $\alpha 7$ and $\alpha 4 \beta 2$ nicotinic receptors and working memory. Neuroscience 109, 757-765. 
Levin, E.D., Petro, A., Rezvani, A.H., Pollard, N., Christopher, N.C., Strauss, M., Avery, J., Nicholson, J., Rose, J.E., 2009. Nicotinic alpha7- or beta2-containing receptor knockout: effects on radial-arm maze learning and long-term nicotine consumption in mice. Behav. Brain Res. 196, 207-213.

Liu, Q., Huang, Y., Shen, J., Steffensen, S., Wu, J., 2012. Functional alpha7beta2 nicotinic acetylcholine receptors expressed in hippocampal interneurons exhibit high sensitivity to pathological level of amyloid ß peptides. BMC Neurosci. 13, 155-166.

Liu, Q., Huang, Y., Xue, F., Simard, A., DeChon, J., Li, G., Zhang, J., Lucero, L., Wang, M., Sierks, M., Hu, G., Chang, Y., Lukas, R.J., Wu, J., 2009. A novel nicotinic acetylcholine receptor subtype in basal forebrain cholinergic neurons with high sensitivity to amyloid peptides. J. Neurosci. 29, 918-929.

Lombardo, S., Maskos, U., 2015. Role of the nicotinic acetylcholine receptor in Alzheimer's disease pathology and treatment. Neuropharmacology 96, 255-262.

Ma, L., Turner, D., Zhang, J., Wang, Q., Wang, M., Shen, J., Zhang, S., Wu, J., 2014. Deficits of synaptic functions in hippocampal slices prepared from aged mice null $\alpha 7$ nicotinic acetylcholine receptors. Neurosci. Lett. 570, 97-101.

Maskos, U., Molles, B.E., Pons, S., Besson, M., Guiard, B.P., Guilloux, J.-P., Evrard, A., Cazala, P., Cormier, A., Mameli-Engvall, M., Dufour, N., Cloëz-Tayarani, I., Bemelmans, A.-P., Mallet, J., Gardier, A.M., David, V., Faure, P., Granon, S., Changeux, J.-P., 2005. Nicotine reinforcement and cognition restored by targeted expression of nicotinic receptors. Nature 436, 103-107.

Matsuyama, S., Matsumoto, A., Enomoto, T., Nishizaki, T., 2000. Activation of nicotinic acetylcholine receptors induces long-term potentiation in vivo in the intact mouse dentate gyrus. Eur. J. Neurosci. 12, 3741-3747.

Morris, R.G.M., 2006. Elements of a neurobiological theory of hippocampal function: the role of synaptic plasticity, synaptic tagging and schemas. Eur. J. Neurosci. 23, 2829-2846.

Mullan, M., Crawford, F., Axelman, K., Houlden, H., Lilius, L., Winblad, B., Lannfelt, L., 1992. A pathogenic mutation for probable Alzheimer's disease in the APP gene at the N-terminus of $\beta$-amyloid. Nat. Genet. 1, 345-347.

Nishimura, I., Uetsuki, T., Dani, S.U., Ohsawa, Y., Saito, I., Okamura, H., Uchiyama, Y., Yoshikawa, K., 1998. Degeneration in vivo of rat hippocampal neurons by wildtype Alzheimer amyloid precursor protein overexpressed by adenovirusmediated gene transfer. J. Neurosci. 18, 2387-2398.

Nordberg, A., 2001. Nicotinic receptor abnormalities of Alzheimer's disease: therapeutic implications. Biol. Psychiatry 49, 200-210.

Nordberg, A., Lundqvist, H., Hartvig, P., Lilja, A., Långström, B., 1995. Kinetic analysis of regional $(S)(-) 11 C$-nicotine binding in normal and Alzheimer brains-in vivo assessment using positron emission tomography. Alzheimer Dis. Assoc. Disord. 9, 21-27.

Oakley, H., Cole, S.L., Logan, S., Maus, E., Shao, P., Craft, J., Guillozet-Bongaarts, A., Ohno, M., Disterhoft, J., Van Eldik, L., Berry, R., Vassar, R., 2006. Intraneuronal beta-amyloid aggregates, neurodegeneration, and neuron loss in transgenic mice with five familial Alzheimer's disease mutations: potential factors in amyloid plaque formation. J. Neurosci. Off. J. Soc. Neurosci. 26, 10129-10140.

Oddo, S., Caccamo, A., Shepherd, J.D., Murphy, M.P., Golde, T.E., Kayed, R., Metherate, R., Mattson, M.P., Akbari, Y., LaFerla, F.M., 2003. Triple-transgenic model of Alzheimer's disease with plaques and tangles: intracellular $A \beta$ and synaptic dysfunction. Neuron 39, 409-421.

Ohm, T.G., 2007. The dentate gyrus in Alzheimer's disease. Prog. Brain Res. 163, $723-740$.

Okada, H., Ouchi, Y., Ogawa, M., Futatsubashi, M., Saito, Y., Yoshikawa, E., Terada, T., Oboshi, Y., Tsukada, H., Ueki, T., Watanabe, M., Yamashita, T., Magata, Y., 2013. Alterations in $\alpha 4 \beta 2$ nicotinic receptors in cognitive decline in Alzheimer's aetiopathology. Brain J. Neurol. 136, 3004-3017.

Orr-Urtreger, A., Göldner, F.M., Saeki, M., Lorenzo, I., Goldberg, L., Biasi, M.D., Dani, J.A., Patrick, J.W., Beaudet, A.L., 1997. Mice deficient in the $\alpha 7$ neuronal nicotinic acetylcholine receptor lack $\alpha$-bungarotoxin binding sites and hippocampal fast nicotinic currents. J. Neurosci. 17, 9165-9171.

Pandya, A., Yakel, J.L., 2011. Allosteric modulator desformylflustrabromine relieves the inhibition of $\alpha 2 \beta 2$ and $\alpha 4 \beta 2$ nicotinic acetylcholine receptors by $\beta$ amyloid1-42 peptide. J. Mol. Neurosci. 45, 42-47.

Paxinos, G., Franklin, K.B.J., 2004. The Mouse Brain in Stereotaxic Coordinates. Academic Press, San Diego, CA, USA.

Paylor, R., Nguyen, M., Crawley, J.N., Patrick, J., Beaudet, A., Orr-Urtreger, A., 1998. $\alpha 7$ nicotinic receptor subunits are not necessary for hippocampal-dependent learning or sensorimotor gating: a behavioral characterization of Acra7deficient mice. Learn. Mem. 5, 302-316.
Picciotto, M.R., Caldarone, B.J., King, S.L., Zachariou, V., 2000. Nicotinic receptors in the brain. Links between molecular biology and behavior. Neuropsychopharmacology 22, 451-465.

Picciotto, M.R., Zoli, M., Léna, C., Bessis, A., Lallemand, Y., LeNovère, N., Vincent, P., Pich, E.M., Brûlet, P., Changeux, J.-P., 1995. Abnormal avoidance learning in mice lacking functional high-affinity nicotine receptor in the brain. Nature 374, 65-67.

Picciotto, M.R., Zoli, M., Rimondini, R., Léna, C., Marubio, L.M., Pich, E.M., Fuxe, K., Changeux, J.P., 1998. Acetylcholine receptors containing the beta2 subunit are involved in the reinforcing properties of nicotine. Nature 391, 173-177.

Schindelin, J., Arganda-Carreras, I., Frise, E., Kaynig, V., Longair, M., Pietzsch, T., Preibisch, S., Rueden, C., Saalfeld, S., Schmid, B., Tinevez, J.-Y., White, D.J., Hartenstein, V., Eliceiri, K., Tomancak, P., Cardona, A., 2012. Fiji: an open-source platform for biological-image analysis. Nat. Methods 9, 676-682.

Shaughnessy, L., Thomas, M.B., Wakefield, J., Chamblin, B., Nair, A., Koentgen, F., Ramabhadran, R., 2005. Lentiviral vector-based models of amyloid pathology: from cells to animals. Curr. Alzheimer Res. 2, 239-247.

Shi, F.-D., Piao, W.-H., Kuo, Y.-P., Campagnolo, D.I., Vollmer, T.L., Lukas, R.J., 2009 Nicotinic attenuation of central nervous system inflammation and autoimmunity. J. Immunol. 182, 1730-1739.

Son, J.-H., Winzer-Serhan, U.H., 2008. Expression of neuronal nicotinic acetylcholine receptor subunit mRNAs in rat hippocampal GABAergic interneurons. J. Comp. Neurol. 511, 286-299.

Squire, L.R., Wixted, J.T., Clark, R.E., 2007. Recognition memory and the medial temporal lobe: a new perspective. Nat. Rev. Neurosci. 8, 872-883.

Tracey, K.J., 2009. Reflex control of immunity. Nat. Rev. Immunol. 9, 418-428.

van der Zanden, E.P., Snoek, S.A., Heinsbroek, S.E., Stanisor, O.I., Verseijden, C., Boeckxstaens, G.E., Peppelenbosch, M.P., Greaves, D.R., Gordon, S., De Jonge, W.J., 2009. Vagus nerve activity augments intestinal macrophage phagocytosis via nicotinic acetylcholine receptor alpha4beta2. Gastroenterology 137, 1029-1039, 1039-4.

Wang, H.-Y., Lee, D.H.S., D’Andrea, M.R., Peterson, P.A., Shank, R.P., Reitz, A.B. 2000a. $\beta$-Amyloid1-42 binds to $\alpha 7$ nicotinic acetylcholine receptor with high affinity implications for Alzheimer's disease pathology. J. Biol. Chem. 275, 5626-5632.

Wang, H.-Y., Lee, D.H.S., Davis, C.B., Shank, R.P., 2000b. Amyloid peptide Aß1-42 binds selectively and with picomolar affinity to $\alpha 7$ nicotinic acetylcholine receptors. J. Neurochem. 75, 1155-1161.

Wang, H., Yu, M., Ochani, M., Amella, C.A., Tanovic, M., Susarla, S., Li, J.H., Wang, H. Yang, H., Ulloa, L., Al-Abed, Y., Czura, C.J., Tracey, K.J., 2003. Nicotinic acetylcholine receptor alpha7 subunit is an essential regulator of inflammation. Nature 421, 384-388.

Whitehouse, P.J., Price, D.L., Struble, R.G., Clark, A.W., Coyle, J.T., Delon, M.R., 1982 Alzheimer's disease and senile dementia: loss of neurons in the basal forebrain. Science 215, 1237-1239.

Wiklund, A., Granon, S., Faure, P., Sundman, E., Changeux, J.-P., Eriksson, L.I., 2009 Object memory in young and aged mice after sevoflurane anaesthesia. Neuroreport 20, 1419-1423.

Wirths, O., Multhaup, G., Bayer, T.A., 2004. A modified $\beta$-amyloid hypothesis: intraneuronal accumulation of the $\beta$-amyloid peptide-the first step of a fatal cascade. J. Neurochem. 91, 513-520.

Woolf, N.J., Butcher, L.L., 2011. Cholinergic systems mediate action from movement to higher consciousness. Behav. Brain Res. 221, 488-498.

Young, J.W., Crawford, N., Kelly, J.S., Kerr, L.E., Marston, H.M., Spratt, C., Finlayson, K., Sharkey, J., 2007. Impaired attention is central to the cognitive deficits observed in alpha 7 deficient mice. Eur. Neuropsychopharmacol. 17, 145-155.

Young, J.W., Finlayson, K., Spratt, C., Marston, H.M., Crawford, N., Kelly, J.S. Sharkey, J., 2004. Nicotine improves sustained attention in mice: evidence for involvement of the alpha7 nicotinic acetylcholine receptor. Neuropsychopharmacology 29, 891-900.

Young, J.W., Meves, J.M., Tarantino, I.S., Caldwell, S., Geyer, M.A., 2011. Delayed procedural learning in $\alpha 7$-nicotinic acetylcholine receptor knockout mice. Genes Brain Behav. 10, 720-733.

Zoli, M., Picciotto, M.R., Ferrari, R., Cocchi, D., Changeux, J.P., 1999. Increased neurodegeneration during ageing in mice lacking high-affinity nicotine receptors. EMBO J. 18, 1235-1244.

Zufferey, R., Donello, J.E., Trono, D., Hope, T.J., 1999. Woodchuck hepatitis virus posttranscriptional regulatory element enhances expression of transgenes delivered by retroviral vectors. J. Virol. 73, 2886-2892. 